\title{
A Malaysian Delphi consensus on managing knee osteoarthritis
}

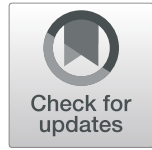

Swan Sim Yeap ${ }^{1^{*}}$ D, Syamsul Rizal Abu Amin², Hazlyna Baharuddin³ ${ }^{3}$ Kar Chai Koh ${ }^{4}$, Joon Kiong Lee ${ }^{5}$, Verna Kar Mun Lee ${ }^{6}$, Nor Hamdan Mohamad Yahaya ${ }^{7}$, Cheh Chin Tai ${ }^{8}$ and Maw Pin Tan ${ }^{9,10}$

\begin{abstract}
Background: The 2013 Malaysian Clinical Practice Guidelines on the Management of Osteoarthritis (OA) recommend a linear step-up approach to manage knee OA. However, patients with knee OA often require a multimodal approach to address OA-related pain symptoms and functional limitations. This consensus aimed to provide doctors with an updated set of evidence-based, clinical experience-guided recommendations to manage knee OA.

Methods: A multi-speciality expert panel consisting of nine Malaysian physicians from different healthcare settings who manage a diverse OA patient population was convened. Using a combination of the ADAPTE process and modified Delphi method, the panel reviewed current evidence on the management of knee OA and synthesised a set of nine recommendations on the management of knee $\mathrm{OA}$, supported by an algorithm that summarises the consensus' core messages.

Results: A multimodal intervention strategy is the mainstay of OA management and the choice of any single or multimodal intervention may vary over the course of the disease. Overall, a non-pharmacological core treatment set of patient education, weight loss and exercise is recommended for all patients. When pharmacotherapy is indicated, symptomatic slow-acting drugs for osteoarthritis are recommended at the early stage of disease, and they can be paired with physical therapy as background treatment. Concurrent advanced pharmacotherapy that includes nonsteroidal anti-inflammatory drugs, intraarticular injections and short-term weak opioids can be considered if patients do not respond sufficiently to background treatment. Patients with severe symptomatic knee OA should be considered for knee replacement surgery. Management should begin with specific treatments with the least systemic exposure or toxicity, and the choice of treatment should be determined as a shared decision between patients and their team of healthcare providers.
\end{abstract}

Conclusions: This consensus presents nine recommendations that advocate an algorithmic approach in the management of patients living with knee $O A$. They are applicable to patients receiving treatment from primary to tertiary care providers in Malaysia as well as other countries.

Keywords: Knee osteoarthritis, Multimodal intervention, Malaysian consensus, Algorithm

\footnotetext{
* Correspondence: swanyeap@gmail.com

'Department of Medicine, Subang Jaya Medical Centre, No. 1, Jalan SS12/1A,

47500 Subang Jaya, Selangor, Malaysia

Full list of author information is available at the end of the article
}

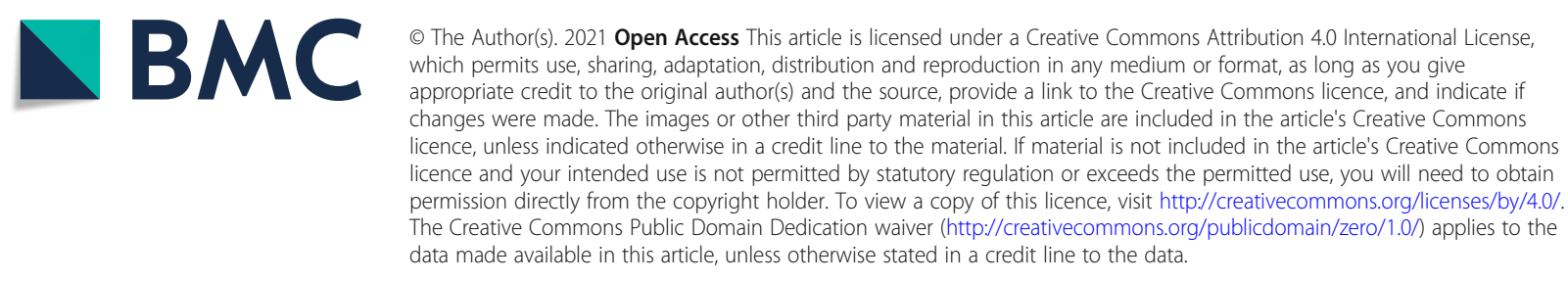




\section{Background}

Osteoarthritis (OA), being the most prevalent form of arthritis, is characterised by progressive cartilage loss with remodelling of adjacent bone, leading to structural changes of the joint, causing pain and functional disability [1]. The pathophysiology of OA includes a slow but inefficient repair process that often compensates for the initial trauma/damage, resulting in a structurally altered but symptom-free joint. When this process fails to compensate ("joint failure"), because of either overwhelming trauma or compromised repair, patients will present with symptomatic OA [2].

Based on the Global Burden of Disease 2010 study, OA of the hip and knee was the 11th highest contributor to global disability, and the global age-standardised prevalence of knee OA was 3.8\% (95\% uncertainty interval, 3.6 to $4.1 \%$ ) [1]. Severe knee pain is an independent predictor of fall risk among the older population [3], and patients with OA have been shown to be at a higher risk of death compared with the general population [4]. Musculoskeletal disorders accounted for $6.3 \%$ of Malaysia's disability-adjusted life years per 100,000 population in 2017 [5]. According to the Community Oriented Programme for the Control of Rheumatic Diseases (COPCORD) study conducted in Malaysia, $64.8 \%$ of all joint-related complaints were regarding the knee; among patients assessed for knee pain, over half showed clinical evidence of OA [6].

Consistent with global trends, Malaysia is also facing an increasing prevalence of OA owing to a combination of risk factors. Age and obesity are two major factors that elevate the risk of OA [7], both of which are increasingly prevalent in Malaysia. In 2019, the percentage of the Malaysian population aged $\geq 65$ years was estimated at $6.7 \%$ out of 32.6 million people; by 2040, the percentage of the older population is expected to reach $14.5 \%[8,9]$. In a cross-sectional survey from the Malaysian Elders Longitudinal Research (MELoR) study, knee pain was present in $33.2 \%$ of 1212 study participants [3]. According to the 2019 Malaysian National Health and Morbidity Survey, the prevalence of overweight and obesity in the country were 30.4 and $19.7 \%$, respectively [10].

The longitudinal Framingham Heart Study first showed that occupations that combine knee bending and physical demands may be an important contributor of radiographic OA [11]. This observation was confirmed by a crosssectional study in Japan that associated kneeling and squatting with lower minimum joint space width and higher osteophyte area - structural changes that are commonly seen in those with knee OA [12]. As an Asian country, the practice of kneeling and squatting is also commonly seen among the Malaysian population [13]. A Malaysian study found that squatting exacerbated discomfort and knee pain in patients with knee OA, which disrupted activities of daily living [14].

Collectively, these risk factors contribute to a significant burden of musculoskeletal disorders in the country; musculoskeletal pain (including knee pain) has been reported as one of the most common reasons for patients to seek medical care in the primary care setting $[6,15$, 16]. The Malaysian Clinical Practice Guidelines (CPG) on the Management of Osteoarthritis (2nd edition) was published in 2013, but has not been updated since to reflect the latest available evidence on the management of knee OA [7]. The current CPG recommends a linear step-up treatment approach, where each intervention is only introduced upon the failure of the previous therapy, indicated by persistent symptoms that affect patients' quality of life (QOL).

In the real-world, the growing burden of chronic diseases (e.g., knee OA) highlighted the need for a more 'proactive' approach in patient management [17]. Based on the individual needs of each patient, physicians can employ a multimodal approach that utilises a combination of pharmacological and non-pharmacological interventions according to the severity of knee OA. Such an approach prevents the deterioration of patient's condition and preserves their QOL.

While current international OA guidelines serve as important references that provide evidence-based disease management recommendations, they often lack localised clinical input that optimises the treatment pathway for specific patient populations [18, 19]. Specifically, international guidelines often do not consider the limitations of drug availability and access in individual countries. To address this gap, an expert panel of specialist physicians and surgeons authored this consensus to provide doctors with a set of evidence-based recommendations with an accompanying algorithm, taking into account drug availability, prescribing preferences, and local practices, that can be used to optimise the management of patients with knee OA in Malaysia.

\section{Methods}

An expert panel consisting of nine Malaysian physicians from different specialties with experience in the management of knee OA was convened. The panel was gathered by two senior consultants, namely SSY and JKL, who recruited seven other panellists based on the following criteria: (i) at least 15 years of clinical experience in managing patients with knee $\mathrm{OA}$ in their respective practice, (ii) still actively treating patients with knee OA (average 60 visits/month), and (iii) representing the unique different healthcare settings in Malaysia (i.e., primary and hospital care; public, private and academic centres). They included three orthopaedic surgeons (two from private and one from academic centres), two rheumatologists 
(one each from private and public/academic centres), an academic family medicine specialist, an academic geriatrician, a private general practitioner, and a public sports medicine physician. The panel's scope of work included developing a set of consensus recommendations and a one-page algorithm on the optimal management practices of knee OA that are relevant to the Malaysian population.

The panel planned to develop a set of evidence-based and clinical-guided consensus using a combination of the ADAPTE process and modified Delphi method [20-22]. SSY and JKL first conducted a literature search on Medline (via PubMed) using the following terms: 'knee', 'osteoarthritis', 'management', 'guideline', and 'recommendation' to identify knee OA guidelines that could be adapted to the Malaysian setting. From a total of 102 search results, the panel identified and appraised 11 clinical guidelines for their relevance and applicability.

Subsequently, four meetings were held between October 2019 and September 2020. At the first meeting, the panel decided that the 2019 European Society for Clinical and Economic Aspects of Osteoporosis, Osteoarthritis and Musculoskeletal Diseases' (ESCEO) algorithm recommendation for the management of knee OA would provide the most appropriate foundation for the development of the Malaysian consensus.

During the second meeting, a total of 15 recommendation statements from the ESCEO 2019 guideline were reviewed by the panel. Each original statement was assessed and debated for their relevance to clinical practice in Malaysia, and six recommendations were unanimously rejected by the panel. Using the remaining nine recommendations as anchor points, the panel performed a second literature review using PubMed (https:// pubmed.ncbi.nlm.nih.gov/) and Google Scholar (https:// scholar.google.com/) to collate evidence that supported each recommendation. Relevant studies published between 2001 and 2020 were identified using these search terms: 'knee osteoarthritis', 'degenerative arthritis', 'knee pain', 'function', 'WOMAC', 'treatment', 'SYSADOA', 'NSAIDs', 'paracetamol', 'intra-articular injection', 'surgery', 'consensus', 'algorithm', and 'Malaysia'.

The search results were then screened using the following criteria: (a) evidence-based management of OA, including pharmacological and non-pharmacological treatment options; (b) complete outcome data as assessed by the Western Ontario and McMaster Universities Arthritis Index (WOMAC), visual analog scale (VAS), Lequesne index, or joint space width (JSW), with comparisons at baseline and end of follow-up periods for all study groups; (c) availability of systematic review, meta-analysis, or randomised controlled trial; and (d) studies in a Malaysian population. Additional studies that were relevant, but not retrieved from the search strategy, were added from the personal files of the panel.

Guided by the compiled evidence (101 published references) and the panel's own clinical experience, nine Malaysian-centric treatment recommendations were synthesised and an associated algorithm was proposed to supplement the recommendations. Next, individual panellists indicated their respective position on each proposed recommendation using a five-point Likert scale ( 1 = strongly disagree, 2 = disagree, $3=$ neutral, $4=$ agree, $5=$ strongly agree) by participating in a blinded online voting exercise. Consensus was defined a priori as a combined 'strongly agree' and 'agree' acceptance rate of $\geq 70 \%$, with no more than one outlier, or $\geq 1$ Likert point from the mean in either direction [23]. Five recommendations (i.e., Recommendations $1-3,7$ and 8) reached a consensus after the first round of voting and were accepted unchanged. The disagreements regarding the other four recommendations (i.e., Recommendations 46 and 9) were resolved at the third meeting through discussion and a second round of open voting.

At the fourth and final meeting, the panel scrutinised each recommendation, along with their respective elaborations, for scientific accuracy and local relevance. All nine recommendations achieved 100\% level of agreement, and the accompanying Malaysian knee OA algorithm was adjusted, until it was unanimously approved, to reflect the disease management principles expounded by the recommendations (Fig. 1).

\section{Results}

\section{Recommendations of knee OA management} Recommendation 1

The group recommends that all patients with osteoarthritis of the knee should be assessed carefully to establish their diagnosis, severity and clinical risk profile before initiating treatment.

Patients who demonstrate symptoms suggestive of knee OA should be assessed carefully at the initial consultation [24]. A comprehensive first assessment is necessary for the implementation of an individualised management strategy to achieve optimal patient outcomes [25]. The initial patient assessment should adopt a biopsychosocial approach and include a review of the individual's physical status, activities of daily living, health education needs, health beliefs, as well as motivation to self-manage and overall psychological state. Additionally, it is also important to ascertain the presence of cardiovascular (CV) disease and other comorbidities during the initial assessment. These assessments should ideally be repeated at regular intervals during the patient's follow-up sessions.

The diagnosis of knee OA can be made clinically based on patient history and physical examination. Persistent 


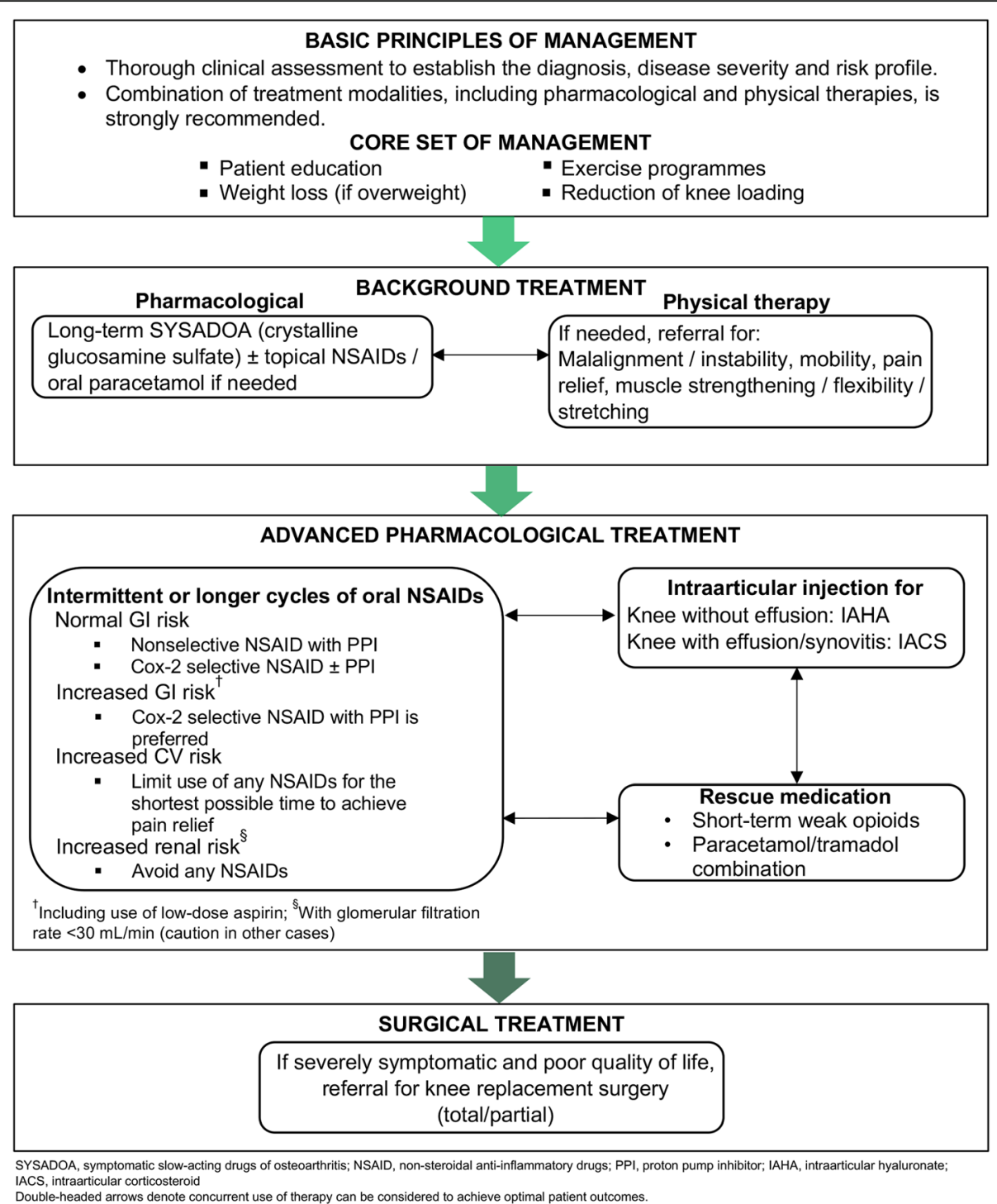

Fig. 1 Malaysian consensus on the management of knee OA (2021): Recommended algorithm

knee pain, morning stiffness of $<30$ min, reduced function (especially an inability to squat), together with risk factors strongly associated with the incidence of knee OA such as age $>50$ years, female gender, higher body mass index, previous knee injury or malalignment, joint laxity, selected occupational or recreational usage, and a positive family history would be suggestive of knee OA. On examination, the signs suggestive of knee OA include crepitus, restricted range of movement, and bony enlargement (Fig. 2) [24]. Additionally, the presence of deformity, instability, periarticular or joint-line tenderness around the knee, pain on patellofemoral compression, and/or Heberden's nodes may also be present in those with knee OA.
In terms of investigation, weight bearing $\mathrm{x}$-rays of the knee is accepted as the current 'gold standard' for the morphological assessment of knee OA, with focal joint space narrowing (JSN), the presence of osteophyte(s), subchondral bone sclerosis, and subchondral 'cysts' being considered classical features of knee OA. However, European League Against Rheumatism (EULAR) recommendations highlighted that plain radiographs should be used as an adjunct as opposed to being a central feature of diagnosis [24]. In adults aged $\geq 45$ years presenting with the above signs and symptoms, a firm diagnosis of knee OA can be made without radiographic assessment or even when the subject's radiograph appears normal. While blood, urine or synovial fluid tests are unnecessary, they 


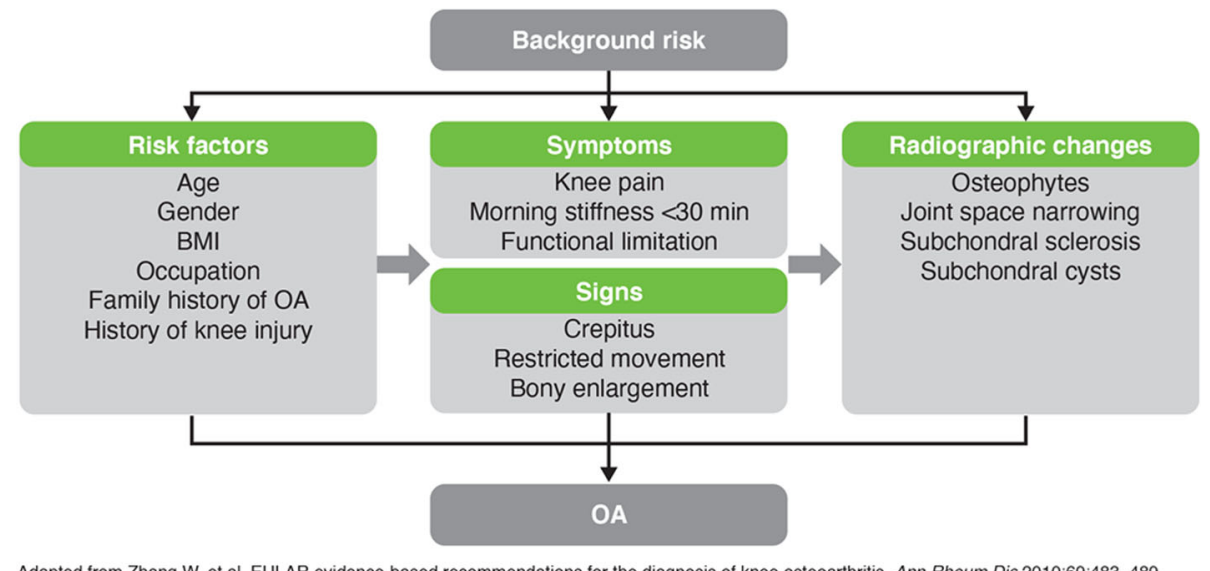

Adapted from Zhang W, et al. EULAR evidence-based recommendations for the diagnosis of knee osteoarthritis. Ann Rheum Dis 2010;69:483-489. $\mathrm{BMI}=$ body mass index

Fig. 2 Major components in the diagnosis of knee OA [24]

may be used to confirm or exclude coexisting inflammatory disease in patients with suggestive symptoms or signs.

\section{Recommendation 2}

The group recommends that treatment should be individualised to each patient's symptoms, and a combination of treatment modalities, including pharmacological and physical therapies, should be used to manage patients with knee osteoarthritis.

According to EULAR recommendations, the individualisation of treatment should be used as the main guiding principle in managing patients with knee OA [24], a position supported by the panel. Specifically, the treatment of knee OA should be personalised as a package of care based on shared decision-making, taking into account the presence of OA risk factors (e.g., age, sex, comorbidity, obesity and adverse mechanical factors), presence of inflammation, severity of structural change, level of pain and restriction of daily activities, along with societal participation and quality of life (QOL).

Randomised controlled trials (RCT) have shown that individualised non-pharmacological management of knee OA resulted in reduced pain (mean difference, 95\% confidence interval $[\mathrm{CI}][0-20$ point scale]: $-1.19,-2.1$ to -0.3 and $-1.01,-1.84$ to -0.19$)$ and improved physical function (mean difference, 95\% CI [0-68 point scale]: $3.65,1.0$ to 6.3 and $3.33,0.78$ to 5.88 ) compared with usual care $[26,27]$.

A comprehensive plan for the management of $\mathrm{OA}$ in an individual patient may include educational, behavioural, psychosocial, and physical interventions, as well as topical, oral, and intraarticular medications [19]. In the 2019 American College of Rheumatology/Arthritis Foundation Guideline for the Management of OA of the Hand, Hip, and Knee, it is suggested that various pharmacological and non-pharmacological options may be used (and reused) at various intervals during the course of a patient's disease [19]. It is important to acknowledge that while some patients may achieve adequate symptom control from a single mode of intervention, others may require sequential or combined use of various interventions to achieve optimal outcomes.

\section{Recommendation 3}

The group recommends the application of a core treatment set, consisting of patient education, weight loss (if overweight), exercise programmes, and reduction of knee loading throughout the management of knee osteoarthritis.

Core treatments are interventions that are considered suitable for use by most patients in almost any scenario, and are considered safe to use in combination with first and second-line pharmacological treatments. Core treatments for knee OA should include arthritis education and structured land-based exercise programmes in combination with weight management (if needed) [28]. A narrative review that aimed to identify all possible risk factors that can be modified postulated that a holistic approach to the management of knee OA may consist of quadriceps muscle-strengthening exercises, supplemented with a proper diet, weight loss, vocational rehabilitation, management of comorbidities, and orthotics [29].

Patient education is a life-long process that plays an integral role in increasing adherence to exercise and weight loss programmes, thus promoting long-term benefits. Patient education should include appropriate educational information, self-management training, and a suitable medium to convey the information. In Malaysia, patient education is particularly important as the use of traditional and complementary medicine (TCM) for knee pain remains widespread owing to the perceived 
risks of allopathic medicine. In a cross-sectional survey, $57.9 \%$ of patients reported prior use of TCM for knee $\mathrm{OA}$; the use of TCM was higher among males (OR, 2.47; 95\% CI, 1.28 to 4.77 ), and those with a longer diagnosis of OA (OR, 1.51; 95\% CI, 1.03 to 2.23 ) or greater severity of knee pain (OR, 2.56; 95\% CI, 1.71 to 3.86) [30].

With the implementation of self-management programmes, cost-efficiency studies have found a reduction in medical visits and healthcare costs after 12 months [31]. As in the EULAR guidelines, we recommend that patients who require lifestyle modification should receive an individualised programme, which consists of long and short-term goals, action plans, regular evaluation and follow-up, along with potential adjustments to the programme as needed [25].

Obesity is a significant and modifiable risk factor for patients with knee OA. Secondary analysis of the Intensive Diet and Exercise for Arthritis (IDEA) RCT found that there were significant dose responses to weight loss for pain $(p=0.01)$, function $(p=0.0006)$, six-minute walk distance $(p<0.0001)$, as well as physical ( $p=$ $0.0004)$ and mental $(p=0.03)$ health-related QOL (HRQOL). Long-term weight loss of 10-19.9\% from baseline body weight has shown significant clinical and mechanistic benefits, and for individuals who had lost at least $10 \%$ of their baseline body weight, an additional $10 \%$ weight loss led to enhanced physical HRQOL, less pain and better function [32]. Importantly, weight loss reduces knee loading and further structural progression of knee OA [33].

Both traditional and non-traditional forms of exercise improve joint-related patient outcomes, mobility, QOL, psychological health, musculoskeletal properties, body composition, sleep and fatigue [34]. Long-term low-tomoderate or strenuous physical activity has not been associated with 10-year incident radiographic knee OA [35]. A systematic review of patients with knee OA found high- and moderate-quality evidence from 44 trials that land-based exercises such as strength training and aerobic exercise reduced pain (standardised mean difference [SMD], $-0.49 ; 95 \% \mathrm{CI},-0.39$ to -0.59$)$ and improved physical function (SMD, $-0.52 ; 95 \% \mathrm{CI},-0.39$ to - 0.64). Additionally, another 13 studies found highquality evidence that land-based therapeutic exercises improved patients' QOL (SMD, 0.28; 95\% CI, 0.15 to 0.40) [36]. Traditional exercises comprising strength, flexibility, and aerobic training are beneficial in improving subjective physical function (e.g., WOMAC, Knee Injury and Osteoarthritis Outcome [KOOS]) and objective function (e.g., six-minute walk test, 30-s chair stand test) for patients with knee OA [34].

The effects of non-traditional modes of exercise such as mind-body exercises (i.e., tai chi and yoga) are deemed effective and safe for all patients with knee OA, regardless of comorbidity and have recently been recommended as part of the core treatment set [28]. A metaanalysis of nine RCTs suggested that tai chi has favourable effects on pain (SMD, $-0.79 ; 95 \% \mathrm{CI},-1.19$ to $-0.39 ; p=0.0001 ; \mathrm{I}^{2}=55 \%$ ), physical function (SMD, -0.86 ; $95 \% \mathrm{CI},-1.20$ to $\left.-0.52 ; p<0.00001 ; \mathrm{I}^{2}=38 \%\right)$, and joint stiffness (SMD, -0.53 ; 95\% CI, -0.99 to $\left.0.08 ; p=0.02 ; \mathrm{I}^{2}=67 \%\right)$. Despite the encouraging results, the evidence that tai chi is effective in patients with OA remains limited owing to the small number of low-bias risk RCTs [37]. A recent meta-analysis of 13 RCTs reported that regular yoga training resulted in improved pain (SMD, -0.98 ; 95\% CI, -1.18 to -0.78 ; $p<0.05$ ), reduced functional disability (SMD, $-1.83 ; 95 \% \mathrm{CI},-2.09$ to $-1.57 ; p<0.05$ ), and enhanced QOL (SMD, 0.80; 95\% CI, 0.59 to 1.01; $p<0.05$ for Short Form 36 Health Survey [SF-36] general health) in patients with knee arthritis (which included those with knee $\mathrm{OA}$ and rheumatoid arthritis) [38].

Soft braces/knee sleeves are commonly utilised because they are easy to use, low in cost and are recommended as a non-surgical intervention for knee OA. A systematic review with meta-analyses on the effects of soft braces/knee sleeves on self-reported pain and physical function in patients with knee OA found that there was moderate improvement in pain (SMD, 0.52; 95\% CI, 0.14 to $0.89 ; p=0.007$ ), in favour of patients wearing a brace compared with those who did not. This effect can be present for up to 24 weeks [39].

Specific to the older population, the positive effects of a home-based exercise programme on the balance and postural stability in Malaysian seniors with $\mathrm{OA}$ and falls have been documented [40]. A systematic review on exercise and weight loss in older patients confirmed that international recommendations on exercise for knee OA also apply to patients aged $70-80$ years [41]. All patients, including older individuals, should thus perform regular land-based exercises, if not in pain, to improve mobility and muscle strength (two to three times a week of 20 60-min sessions, depending on the type of exercise) and overweight patients who are unaffected by sarcopenia should be encouraged to lose weight. Moreover, another systematic review found that self-management education programmes in older Malaysian patients with knee OA improved health perception, treatment adherence and facilitated shared decision-making between the patient and physician [33].

\section{Recommendation 4}

The group recommends the use of crystalline glucosamine sulphate as background therapy for the management of knee osteoarthritis, with as needed topical nonsteroidal anti-inflammatory drugs and/or oral paracetamol. Background pharmacological therapy can be 
initiated concurrently with prescribed physical therapies when indicated.

Symptomatic slow-acting drugs for osteoarthritis (SYSADOAs) are agents that improve symptoms and/or function and, ideally, also inhibit structural disease progression [42]. Some of the pharmacological agents regarded as SYSADOAs include glucosamine, chondroitin sulphate (CS), diacerein, and avocado/soybean unsaponifiables (ASU). The current Malaysian CPG does not prioritise the use of SYSADOAs in the treatment of knee OA [7]. A survey among primary care physicians found that only $60 \%$ of the physicians surveyed have prescribed glucosamine in their practice [43].

Three formulations of glucosamine commonly used to treat knee $\mathrm{OA}$ are crystalline glucosamine sulphate (CGS; a complex molecule obtained using a proprietary semi-synthetic route and stabilisation process [44]), noncrystalline glucosamine sulphate (GS) and glucosamine hydrochloride $(\mathrm{GHCl})$. It is important to distinguish between the different glucosamine formulations as the clinical efficacy data is different for each preparation. Recent studies on knee OA found that only glucosamine formulations containing CGS reliably demonstrated clinical efficacy in pain and function [42, 45-49]. Given as a highly bioavailable, once daily dose of $1500 \mathrm{mg}$, CGS consistently delivered plasma levels of around $10 \mu \mathrm{mol} / \mathrm{L}$ - the level required to inhibit IL-1-induced expression of genes involved in the pathophysiology of joint inflammation and tissue destruction $[42,48]$.

Pooled results from studies on glucosamine formulations found that preparations containing CGS improved pain (SMD, $-0.47 ; 95 \% \mathrm{CI},-0.72$ to -0.23 ) and physical function (SMD, $-0.47 ; 95 \% \mathrm{CI},-0.82$ to -0.12 ) in $\mathrm{OA}$
[46]; this benefit was not observed in non-CGS formulations [48]. In a network meta-analysis of long-term ( $>1$ year) trials of any pharmacological intervention for knee OA, only CGS was consistently effective in reducing knee OA pain (effect size [ES], 0.29; 95\% CI, 0.09 to 0.49), improving physical function and joint structure changes (Fig. 3) [50]; an ES score $>0.20$ is considered clinically relevant in chronic pain conditions [51].

Additionally, patients with knee OA who received CGS therapy regularly for over 3 years did not experience any significant JSN, which suggests that CGS may slow disease progression $[52,53]$. Furthermore, long-term therapy with CGS reduced the need for concomitant rescue analgesia, including non-steroidal anti-inflammatory drugs (NSAIDs; odds ratio [OR], 0.64; 95\% CI, 0.45 to 0.92) [54], and subsequent total knee replacement (TKR) surgery (relative risk [RR], $0.43 ; 95 \% \mathrm{CI}, 0.20$ to 0.92 ) compared with placebo [55].

Other glucosamine preparations such as $\mathrm{GHCl}$ and non-CGS preparations have been repeatedly shown to be ineffective in OA $[56,57]$. The lack of appropriate stabilisation of GS impacts the availability of the active compound; an investigation of 14 commercially available preparations of GS found that the amount of the active ingredient varied from 59 to $138 \%$ of the labelled dose [42]. Glucosamine formulations in combination with chondroitin may be of variable pharmaceutical quality, but a few trials have demonstrated efficacy in knee OA. In a double-blinded RCT, patients who received GS/CS combination had significantly reduced JSN at 2 years (mean difference, 0.10; 95\% CI, 0.002 to 0.20 ) compared with placebo [58]. In addition, a comparative analysis found that glucosamine/chondroitin could improve pain

Intervention [trials, pts]
Analgesics
Acetaminophen [1, $n=27]$
SYSADOA and disease modifiers
Chondroitin sulphate (CS) [5, $n=731$ ]
Diacerein [1, $n=85]$
Glucosamine sulphate $[2, n=207]$
Glucosamines ${ }^{*}[3, n=325]$
Glucosamines + CS [2, $n=280]$
NSAIDs
Celecoxib [3, $n=690]$
Diclofenac [5, $n=1090]$
Etoricoxib $[2 . n=780]$
Indomethacin $[1, n=202]$
Naproxen $[4, n=659]$

Intervention [trials, pts]

Acetaminophen [1, n=27] Chondroitin sulphate (CS) $[5, n=731]$ Diacerein [1, n=85] Glucosamines * $[3, n=325]$ NSAIDs Naproxen $[4, n=659]$
SMD (95\% Crl)

$0.24(-0.36,0.85)$

$-0.06(-0.17,0.05)$

$-0.04(-0.30,0.22)$

$-0.29(-0.49,-0.09)$

$-0.11(-0.26,0.04)$

$-0.13(-0.29,0.03)$

$-0.18(-0.35,-0.01)$

$-0.01(-0.22,0.20)$

$-0.10(-0.35,0.15)$

$0.04(-0.15,0.22)$

$-0.08(-0.39,0.23)$
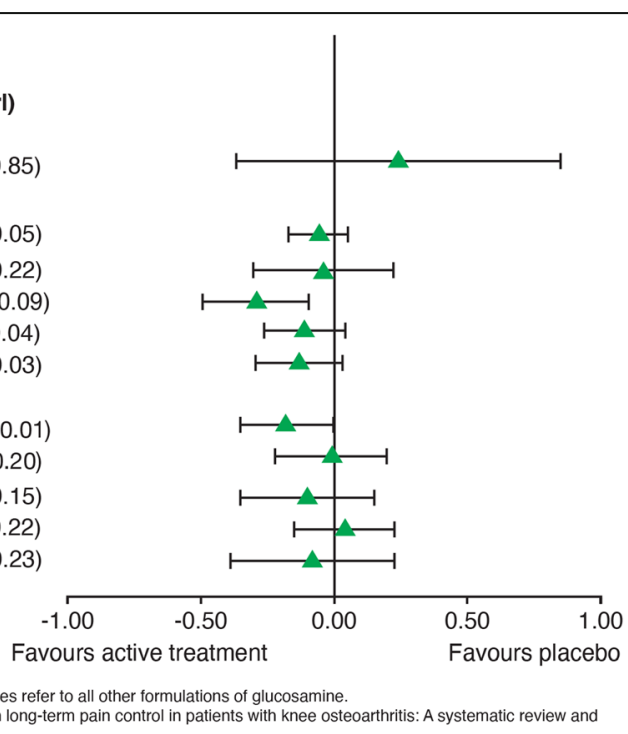

"Glucosamine sulphate refers to crystalline sulphate (CGS), while glucosamines refer to all olher
Adapted from Gregori D, et al. Association of pharmacological treatments with long-term pain control in patients with knee osteoarthritis: A systematic review and Adapted from Gregori D, et al. Association of pha-analysis. JAMA 2018;320:2564-2579.

Fig. 3 Long-term treatment effects of different pharmacological agents for knee OA that are available in Malaysia based on a meta-analysis that excluded trials at high risk of bias [50] 
and physical function in knee and hip OA, albeit to a much lesser degree compared with oral NSAIDs [59].

Diacerein is an anthraquinone derivative with antiinflammatory activity. A systematic review found that diacerein provided minimal pain reduction in both knee and hip OA (RR, 0.85; 95\% CI, 0.72 to 0.99); while some benefit in JSN was observed, it was only clinically relevant in hip OA [60]. Although diacerein was found to be as efficacious as CGS when analysed for symptom relief in a network meta-analysis, it was also associated with more gastrointestinal (GI) adverse events (AEs) (SMD, 2.00; 95\% CI, 0.69 to 5.74) compared with placebo [61]. Based on available evidence, diacerein may be used as an alternative treatment in patients with knee OA who have contraindications to NSAIDs or paracetamol [62]. However, caution has to be taken with diacerein treatment owing to an increased risk of diarrhoea (RR, 3.51; 95\% CI, 2.55 to 4.83 ; $p<0.0001$ ) compared with placebo [63].

ASU, a mixture of vegetable extracts taken from avocado and soybean oils, at doses of 300 and $600 \mathrm{mg} /$ day, is associated with improvements in pain, stiffness and physical function in knee OA, and subsequently a reduced need for rescue analgesia [64]. A systematic review of RCTs found that ASU significantly reduced pain as measured by visual analogue scale assessment (weighted mean difference, $-9.64 \mathrm{~mm} ; 95 \% \mathrm{CI}$, 17.43 to -1.84 ) in patients with knee OA compared with placebo [65]. However, ASU did not significantly improve joint structure or prevent JSN compared with placebo [66].

As safety data vary between SYSADOA agents as well as individual formulations, caution should be taken when selecting the appropriate agent for knee OA. A systematic review on the safety of SYSADOAs found that CGS, CS and ASU were not associated with any increased odds of AEs compared with placebo [67], although the evidence on ASU remains inconclusive as studies on its use have included concomitant OA medications. Diacerein has been associated with significantly increased odds of total AEs (especially GI-related AEs), including dermatological disorders and withdrawals due to AEs compared with placebo [67]. The judicious choice of SYSADOA formulation is essential to maximise clinical benefit, patient adherence and satisfaction with treatment [45].

For OA pain that occurs in spite of background CGS therapy, paracetamol is recommended for 'as required' therapy as the evidence for its efficacy in regular longterm use is uncertain with potential safety concerns. Paracetamol is widely regarded as an inexpensive firstline option for analgesia [50], and its use remains driven by the absence of safer therapeutic alternatives, as both oral NSAIDs and opioids are associated with potentially serious AEs [68]. Paracetamol is often used to relieve mild-to-moderate pain at doses of 600/650 (numberneeded-to-treat [NNT], 4.6;95\% CI, 3.9 to 5.5$)$ and $1000 \mathrm{mg}$ (NNT, 3.8; 95\% CI, 3.4 to 4.4 ), and is as efficacious as aspirin 600/650 mg [69]. However, there is evidence showing that paracetamol lacked both short- and long-term efficacy in improving pain and physical function in knee OA $[39,57]$. In a network meta-analysis of pharmacological interventions in knee OA, paracetamol was the least efficacious intervention (ES, 0.18; 95\% CI, 0.04 to 0.33 ), providing no clinically significant improvement on stiffness and physical function [70].

Several studies have raised concerns over the safety profile of long-term paracetamol therapy. A systematic literature review of observational studies found a considerable degree of GI, CV and renal AEs with chronic paracetamol use when dosed at the upper end of standard analgesic doses (up to $4 \mathrm{~g} /$ day) $[68,71]$. One study found a significantly increased relative rate of mortality in patients prescribed paracetamol compared with nonusers (RR, 1.14; 95\% CI, 1.10 to 1.18) [72]. Moreover, consumption of paracetamol at high doses or frequencies was associated with an increased risk of myocardial infarction (MI) and stroke (RR, 1.17 and 1.30; 95\% CI, 1.04 to 1.32 and 1.19 to 1.41 , respectively) [72], a doseresponse increase in OR of $>30 \%$ with respect to reduced estimated glomerular filtration rate, and $>0.3 \mathrm{mg} /$ $\mathrm{dL}(>25 \mu \mathrm{mol} / \mathrm{L})$ increase in serum creatinine compared with non-users [73]. However, occasional-to-moderately frequent intake of paracetamol does not appear to impair kidney function [74].

Topical NSAIDs may be added to a patient's treatment regimen if they remain symptomatic despite background pharmacological therapy with SYSADOAs, and/or if rescue analgesia with paracetamol provides insufficient symptom relief. The short-term efficacy of topical NSAIDs, up to 2 weeks, in knee OA is well established [75-78]. However, there is no trial data to support the long-term use of topical NSAIDs in OA [75]. Data from a systematic review showed that topical NSAIDs were superior to placebo in relieving pain (SMD, - 0.30; 95\% $\mathrm{CI},-0.40$ to -0.20 ) and improving function (SMD, $0.35 ; 95 \% \mathrm{CI},-0.45$ to -0.24 ) in OA. Of all topical NSAIDs, diclofenac patches were most effective for OA pain (SMD, $-0.81 ; 95 \% \mathrm{CI},-1.12$ to -0.52 ) [78].

Topical NSAIDs were associated with a lower risk of systemic AEs compared with oral NSAIDs owing to lower systemic absorption [79], albeit with an increased risk of mild local skin reactions compared with placebo [76]. There was no significant difference in the odds for GI AEs between topical NSAIDs and placebo (OR, 0.96; 95\% CI 0.73-1.27) [80]. Thus, topical NSAIDs may be safely used as shortterm add-on pain relief, particularly in patients at increased risk of systemic AEs (e.g., older persons, multiple comorbidities). 


\section{Recommendation 5}

The group recommends intermittent or longer cycles of oral non-steroidal anti-inflammatory drugs (NSAIDs; selective or non-selective) as advanced pharmacological treatment for patients who are still symptomatic after receiving background pharmacological and/or physical therapies. The use of oral NSAIDs should be based on an individual patient's risk profile.

Oral NSAIDs (non-selective or cyclooxygenase-2 [COX-2] selective) may be prescribed for patients with knee OA who present with moderate-to-severe pain, or those who remain symptomatic despite background therapy with CGS, with add-on topical NSAIDs and/or oral paracetamol. Oral NSAIDs have a moderate effect in pain relief and a greater efficacy (ES, 0.29; 95\% CI, 0.22 to 0.35 ) compared with paracetamol (ES, $0.14 ; 95 \%$ CI, 0.05 to 0.22 ) [81]. A network meta-analysis found that oral NSAIDs (celecoxib 200/400 mg, diclofenac 100/ $150 \mathrm{mg}$, etoricoxib $60 / 90 \mathrm{mg}$, ibuprofen $2400 \mathrm{mg}$, naproxen $1000 \mathrm{mg}$ daily) improved pain in OA compared with placebo. Among maximally-approved doses, diclofenac $150 \mathrm{mg} /$ day (ES, 0.57 ; $95 \% \mathrm{CI}, 0.45$ to 0.69 ) and etoricoxib $60 \mathrm{mg} /$ day (ES, $0.58 ; 95 \% \mathrm{CI}, 0.43$ to 0.74 ) were most likely to provide the greatest efficacy on pain and physical disability [82].

Studies have shown that COX-2 selective and nonselective NSAIDs were similarly effective in managing pain [81]; the choice of NSAID depends on each individual agent's safety profile and patients' comorbidities [79]. Recent meta-analyses suggested that all NSAIDs have the potential for GI, CV and renal toxicity, particularly in older patients with multiple comorbidities such as hypertension, diabetes, or congestive cardiac failure [83]. Even though COX-2 selective NSAIDs were developed to avoid GI toxicity associated with non-selective NSAI Ds [84], a large meta-analysis found that all NSAIDs were associated with an increased risk for GI AEs; compared with placebo, higher risks of upper GI complications were found with COX-2 inhibitors (rate ratio, 1.81; 95\% CI, 1.17 to 2.81), diclofenac (rate ratio, 1.89; 95\% CI, 1.16 to 3.09 ), ibuprofen (rate ratio, 3.97; 95\% CI, 2.22 to 7.10 ), and naproxen (rate ratio, $4.22 ; 95 \% \mathrm{CI}, 2.71$ to 6.56) [85]. However, the risk of GI AEs may be reduced by the co-administration of a proton pump inhibitor (PPI) [79].

A meta-analysis of six RCTs found no significant differences in the rates of upper GI AEs between COX-2 selective NSAIDs and non-selective NSAIDs with concurrent PPIs ( $\mathrm{Z}$ score, $1.67 ; p=0.09$ ). In addition, there was no significant difference in GI symptoms (RR, 1.10; 95\% CI, 0.88 to 1.39 ) or CV risk (RR, 1.67; 95\% CI, 0.78 to 3.59 ) between both groups [86]. Separately, one metaanalysis reported that non-selective NSAIDs were associated with an increased risk of acute kidney injury (pooled risk ratio, 1.58 to 2.11 ) compared with placebo. An elevated risk was also found for celecoxib, although this did not reach statistical significance (pooled risk ratio, 1.25 ; 95\% CI, 0.79 to 1.97 ) [87].

In terms of $\mathrm{CV}$ risk, one meta-analysis reported that the incidence of major vascular events (i.e., non-fatal MI or stroke, death from vascular cause) was increased by the use of COX-2 inhibitors (rate ratio, 1.37; 95\% CI, 1.14 to $1.66 ; p=0.0009$ ) and diclofenac (rate ratio, 1.41 ; $95 \% \mathrm{CI}, 1.12$ to $1.78 ; p=0.0036$ ) compared with placebo. The risk of hospitalisation for heart failure [HHF] is roughly doubled by all NSAID regimens [85].

When prescribing an NSAID, due consideration should be given to each patient's GI and CV risk profile. Patients with elevated GI risk should be prescribed either a COX-2 selective NSAID, or a non-selective NSAI $\mathrm{D}$ with concomitant PPI therapy [88]. In patients with a high GI and CV risk, the use of NSAIDs should be discouraged; if necessary, a non-selective NSAID with a lower CV risk (e.g., naproxen), may be prescribed in combination with a PPI [81].

\section{Recommendation 6}

The group recommends the use of intraarticular hyaluronate (IAHA) or intraarticular corticosteroids (IACS) in patients who have contraindications to oral non-steroidal anti-inflammatory drugs (NSAIDs), or if patients are still symptomatic despite the use of oral NSAIDs. In patients with knee effusion or synovitis, the use of IACS is preferred.

Intraarticular (IA) therapy is a local treatment modality that avoids AEs commonly seen with systemic agents [89]; two IA agents widely used in the treatment of knee $\mathrm{OA}$ are intraarticular hyaluronate (IAHA) and intraarticular corticosteroids (IACS). The proposed mechanism behind the clinical benefit seen with IAHA acts via two pathways: (i) mechanical viscosupplementation of the joint, providing greater lubrication and shock absorption, and (ii) re-establishment of joint homeostasis via endogenous HA production [90].

A Malaysian study found that IAHA, dosed three times at one-week intervals, improved pain and function in patients with knee OA at 2 weeks, with further improvements seen at both eight- and 24-weeks postinjection [91]. A meta-analysis reported that it was efficacious in pain relief after 4 weeks of treatment initiation (ES, $0.31 ; 95 \% \mathrm{CI}, 0.17$ to 0.45 ), reached its peak effectiveness at 8 weeks (ES, $0.46 ; 95 \% \mathrm{CI}, 0.28$ to 0.65 ), and exerted a residual detectable effect at 24 weeks (ES, $0.21 ; 95 \% \mathrm{CI}, 0.10$ to 0.31 ). Despite its slow onset, the peak efficacy of IAHA was greater than that of other analgesics commonly used in OA (i.e., paracetamol [ES, 0.13; $95 \% \mathrm{CI}, 0.04$ to 0.22 ], non-selective NSAIDs [ES, 
0.29; $95 \% \mathrm{CI}, 0.22$ to 0.35 ], and COX-2 inhibitors [ES, 0.44; $95 \% \mathrm{CI}, 0.33$ to 0.55$]$ ) [51].

In a separate network meta-analysis, IAHA was more effective in relieving pain (ES, 0.34; 95\% Cl, 0.26-0.42) compared with IA placebo at 3 months [92]. A systematic review of RCTs with a low risk of bias concluded that IAHA significantly reduced pain and improved function compared with placebo [93], and real-world evidence showed a reduction in the need for concomitant rescue analgesia, as well as the potential to delay disease progression and the need for TKR surgery [90]. A retrospective review of 45 Malaysian patients with knee OA found that 11 patients $(24.4 \%)$ no longer required further treatment for the disease after receiving IAHA [94].

However, IAHA is positioned later in the treatment algorithm compared with oral NSAIDs [95], owing to the need for repeated injections by a trained healthcare provider and the inherent higher cost of treatment. The disease-modifying effects of IAHA have been validated in several retrospective database analyses which found that IAHA delayed the need for TKR by approximately 2 years; in patients who received five or more courses of IAHA, TKR was delayed by up to 3.6 years [96-98].

In terms of safety, a network meta-analysis of $18 \mathrm{HA}$ products involving 13,042 patients found a very low incidence of AEs (8.5\%) - most commonly transient local reactions (e.g., pain, swelling and arthralgia) which subsided rapidly. In the study, the incidence of AEs was similar between different HA formulations and was not significantly different compared with placebo [99].

IACS is indicated for short-term pain relief in patients with knee OA with evidence of synovitis. A Cochrane review found small benefits with IACS with regard to pain reduction (SMD, $-0.40 ; 95 \% \mathrm{CI},-0.58$ to -0.22 ) and physical function (SMD, -0.33 ; $95 \% \mathrm{CI},-0.56$ to 0.09), although the evidence was of low quality [100]. Similarly, a network meta-analysis found that IACS afforded a greater reduction in pain (ES, 0.32; 95\% CI, 0.16 to 0.47 ) - without any significant improvement in function - compared with placebo [92].

The benefits of IACS in knee OA may be limited by disease severity and structural damage. In an open-label trial examining the effects of structural factors on IACS therapy, patients with more severe knee damage - based on either magnetic resonance imaging or x-ray scans were found to have poorer response to therapy compared with those with milder structural damage. Higher Kellgren and Lawrence and JSN scores, as well as more extensive structural damage were associated with poorer short-term outcomes [101]. Moreover, the safety of long-term IACS therapy remains a concern [102].

In a study examining the long-term effects of IACS, patients with knee OA were randomised to receive either regular IACS or IA placebo every 3 months for a total duration of 2 years. Patients in the IACS arm experienced significantly greater cartilage volume loss (between-group difference, $-0.11 \mathrm{~mm} ; 95 \% \mathrm{CI},-0.20$ to $-0.03 \mathrm{~mm}$ ) compared with those who received IA placebo with no significant difference in pain relief observed between both groups. Although the loss of cartilage did not exacerbate existing OA symptoms, it may speed up disease progression and is associated with higher rates of arthroplasty. Thus, the use of long-term, regular IACS for patients with symptomatic knee OA should be avoided [103].

A meta-analysis of seven head-to-head RCTs comparing IAHA with IACS found that the pattern of relative efficacy varied over time. From baseline to week 4, IACS appeared to be relatively more effective for pain (ES, $0.39 ; 95 \% \mathrm{CI},-0.65$ to -0.12 ) compared with IAHA. At week 4, there was no significant different in pain relief between both agents (ES, $-0.01 ; 95 \% \mathrm{CI},-0.23$ to 0.21 ). From week 8 and beyond, IAHA was more efficacious (efficacy at week 8: ES, 0.22 ; $95 \% \mathrm{CI},-0.05$ to 0.49 , week 12: ES, 0.35 ; $95 \%$ CI, 0.03 to 0.66 , and week 26: ES, 0.39; 95\% CI, 0.18 to 0.59 ) [104]. A different meta-analysis also showed that although IACS was more effective in the short-term (i.e., two to four weeks), IAHA exhibited greater efficacy with long-term therapy (i.e., 6 months) [102].

Viscosupplementation with IAHA is only indicated in the absence of acute inflammation (i.e., no clinically detectable effusion) [105]. In patients with active knee inflammation/effusion, IACS is the preferred injectable agent [18]. Importantly, the combination of IACS and IAHA in a single injection should be avoided as clinical benefit of the combination does not last over 1 week, while there is an increased risk associated with corticosteroid use [105].

\section{Recommendation 7}

The group recommends the judicious use of short-term weak opioids or paracetamol/tramadol combination as rescue medication in patients who have not achieved satisfactory pain control despite the use of oral nonsteroidal anti-inflammatory drugs and/or intraarticular injections.

Tramadol, a weak opioid, is recommended by the 2013 Malaysian OA CPG as an immediate step-up treatment in patients who experience inadequate pain relief with paracetamol and/or topical NSAIDs [7]. However, tramadol is seldom used in clinical practice as it is associated with an increased risk of falls, particularly among the older population [7].

In a systematic review on the safety of opioid analgesics in older adults ( $>60$ years) suffering from musculoskeletal pain, opioids had a small beneficial effect on pain (SMD, $-0.27 ; 95 \% \mathrm{CI},-0.33$ to -0.20 ) and 
function (SMD, $-0.27 ; 95 \% \mathrm{CI},-0.36$ to -0.18 ), which was not affected by dose or treatment duration. Of the studies included, tramadol in both immediate-release (IR) and sustained-release (SR) formulations significantly improved pain ( $p=0.045$ and $p<0.01$, respectively) and function ( $p=0.033$ and $p<0.01$, respectively) compared with placebo; additionally, the combination of tramadol/ paracetamol significantly improved pain $(p=0.0095)$, and function $(p=0.0449)$ compared with placebo [106].

A comparative review of analgesics in knee OA found no significant differences in WOMAC pain reduction between less potent opioids (e.g., tramadol), potent opioids (e.g., hydromorphone, oxycodone), and oral NSAI Ds [107]. A separate meta-analysis also showed that opioids and oral NSAIDs (both non-selective and COX-2 selective) had comparable efficacy in relieving OA pain [108]. Even though tramadol has a preferable safety profile (i.e., fewer GI and CV AEs) compared with oral NSAIDs [109], several studies have cited potential safety issues associated with the use of opioids in OA. A Cochrane review found that tramadol was associated with a greater risk of withdrawals due to AEs (RR, 2.64; 95\% CI, 2.17 to 3.20) compared with placebo [109]. A recent safety meta-analysis found that the use of oral opioids - in both IR and SR formulations - was associated with an increased risk for GI, central nervous system and dermatological AEs compared with placebo [110].

The tolerability of tramadol SR may be improved via a slow upward dose titration from 50 to $100 \mathrm{mg}$, with no impact on its efficacy $[111,112]$. An observational study found significantly fewer AEs (e.g., nausea, dizziness) and lower rates of treatment discontinuation due to AEs in the dose-escalation group (50 $\mathrm{mg} \mathrm{BD}$ ) versus the control group (100 mg BD) (5.6\% vs $12.6 \% ; p=0.001)$, with similar efficacy [111]. An RCT involving 250 Korean patients with knee OA managed with a stable dose of NSAIDs found that the titration of tramadol/paracetamol doses was associated with improved tolerability and significantly lower discontinuation rates due to AEs compared with non-titration (10.5\% vs $26.2 \% ; p<0.001)$; of note, both regimens displayed a similar efficacy in pain relief as measured by the Korean-WOMAC score $(-12.86$ vs -12.52 , respectively) [112]. Thus, a slow upward titration of tramadol improves tolerability without compromising pain relief.

Owing to safety and potential dependency issues associated with opioids in OA, it is recommended that opioids be reserved only for short-term pain relief, after exhausting other analgesic options.

\section{Recommendation 8}

The group recommends the concurrent use of individual advanced pharmacological therapies (oral non-steroidal anti-inflammatory drugs, intraarticular injections, and rescue medication) when patients do not respond sufficiently to monotherapy. Patients should be assessed regularly, and treatment adjusted based on their response.

The use of concurrent therapies in knee OA is not uncommon; a large Korean study involving 2,016,516 patients with knee OA (mean age, 63.2 years) found that patients were commonly treated with combination regimens. At least $37.2 \%$ of the patients were managed on two medications (e.g., paracetamol, SYSADOA, corticosteroids), while another $16.6 \%$ of patients were managed on three medications [113]. In Malaysia, the combination of NSAIDs with other analgesics is an established practice of primary care physicians in managing knee OA [43].

A multicentre double-blinded RCT found that the addition of tramadol/paracetamol $(37.5 \mathrm{mg} / 325 \mathrm{mg})$ to concomitant NSAID therapy significantly improved average daily pain intensity and pain relief scores $(p<$ 0.001) compared with placebo in the treatment of OA flare pain. In the study, the addition of tramadol/paracetamol significantly improved pain (WOMAC score, 2.56 vs $-2.02 ; p=0.004$ ), physical function (WOMAC score, -2.22 vs $-1.77 ; p=0.013$ ), and overall well-being (WOMAC score, -2.37 vs $-1.89 ; p=0.008$ ) scores compared with NSAID therapy alone. Tramadol/paracetamol was well tolerated by patients - with nausea, vomiting, and dizziness being the most common reported AEs and no serious AEs reported [114].

The chronic use of anti-inflammatory drugs (i.e., oral NSAIDs) is associated with an increased risk of upper GI AEs; which is dose dependent and increases when multiple oral NSAIDs are prescribed simultaneously. Hence, only one anti-inflammatory drug should be prescribed - at the lowest effective dose - in order to minimise the risk of serious upper GI AEs [115]. As the natural course of OA may be one of intermittent flares followed by resolution, usage of additional therapeutic options such as IA injections or other short term rescue medication in addition to oral NSAIDs for an acute flare is an option. However, the use of concurrent therapies should be for the shortest possible time and stopped when the flare has resolved.

Patients with knee OA may experience a variety of additional symptoms (e.g., mood disorders, altered sleep, impaired coping skills) resulting from pain and functional limitations associated with $\mathrm{OA}$ and/or other comorbidities. Thus, patients with knee OA may be treated with a combination of pharmacological and non-pharmacological interventions. A multimodal treatment plan may better address patients' comorbidities, as well as improve overall well-being and rate of treatment success compared with management strategies using a single pharmacological agent [19]. 
The choice of any single or multimodal intervention in knee OA may vary over the course of the disease, or with patient and physician preferences, and should be decided as a shared decision between the patient and doctor. Physicians should exercise caution when prescribing pharmacological agents, and management should begin with treatments with the least systemic exposure or toxicity [19].

\section{Recommendation 9}

The group recommends knee replacement surgery (total or partial) for patients with severe/advanced knee osteoarthritis.

A network meta-analysis on surgical interventions in the management of knee OA found that osteotomy, unilateral knee arthroplasty (UKA), TKR and arthroscopic surgery effectively improved function scores of patients with knee OA. TKR displayed better long-term efficacy compared with other surgical interventions, while UKA and osteotomy were associated with better short-term efficacy [116].

Short- to medium-term studies have shown that TKR is a safe and cost-effective method for relieving pain and restoring function in patients with severe/advanced knee OA [117]. TKR is appropriate when all previous treatment modalities have failed, if the patient is severely symptomatic, or if there is significant loss in HRQOL [116-118]. TKR effectively restores mobility, improves pain, function and HRQOL in patients with severe/advance knee OA [117].

Indications for TKR include pain refractory to nonsurgical treatments, significant functional impairment/ disability in activities of daily living, radiographic findings (e.g., JSN, bone sclerosis), and failure of conservative treatment to manage knee OA symptoms, such as patients who remain symptomatic despite regular analgesia [119]. In addition, TKR may be considered for patients at high risk of systemic AEs associated with oral NSAIDs, owing to its preferable safety profile [120]. Following TKR, a systematic review found that there were significant intermediate- and long-term benefits with respect to both disease-specific and generic HRQOL, in particular pain $(1.72 ; 95 \% \mathrm{CI}, 0.97$ to $2.46 ; p<0.00001)$ and function $(1.26 ; 95 \% \mathrm{CI}, 0.87$ to $1.64 ; p<0.00001)$, leading to positive patient satisfaction [118].

Patient-reported outcomes in TKR may be influenced by ethnic differences [121]. A study in an Asian cohort found high levels of patient satisfaction post-TKR $(92.8 \%)$, which correlated with postoperative WOMAC function scores $(p=0.028)$, postoperative WOMAC total scores $(p=0.040)$, and expectations being met $(p=$ 0.033) [122].

Although TKR is a routine and safe procedure in the management of severe/advanced knee OA (survival rates at 1 year: 99\%, and 10 years: $84 \%$ ), up to $20 \%$ of patients have reported dissatisfaction with the overall outcome of TKR [118]. Of note, this percentage has persisted despite improvements in surgical techniques and postoperative care. A systematic review found that the degree of patient dissatisfaction post-TKR could be influenced by several key factors, including patient expectations prior to surgery, the degree of improvement in knee function, as well as pain relief following surgery [123].

In terms of safety, surgical intervention is associated with less AEs and complications compared with the use of long-term pharmacological agents, particularly NSAI Ds. A systematic review found that naproxen was associated with significantly higher mortality rates (hazard ratio [HR], 3; 95\% CI, 1.9 to 4.6) compared with TKR (HR, 0.79 ; $95 \% \mathrm{CI}, 0.66$ to 0.92 ). Additionally, GI complications were highest with the use of diclofenac (OR, 4.77; 95\% CI, 3.94 to 5.76), but lowest with TKR (HR, 0.6; $95 \%$ CI, 0.49 to 0.75 ) [120].

\section{Discussion}

The 2013 Malaysian CPG on the Management of Osteoarthritis, along with several other international guidelines, recommends a linear step-up approach in managing knee OA. However, pain symptoms and functional limitations experienced by arthritic patients often respond poorly to monotherapy and should instead be managed by a concurrent multimodal strategy. In the real world, simultaneously administering a combination of therapies to manage knee OA is already part of clinical practice [40, 43], and this Malaysian consensus seeks to shine light on the value of a multimodal intervention strategy in improving patient outcomes and QOL based on published evidence and clinical experience (Fig. 1).

When managing patients with knee OA whose condition has been carefully assessed, there is an overwhelming consensus that support patient education, weight management, exercise programmes, and the reduction of knee loading as the foundation of individualised treatment plan. Nonetheless, physiotherapy and non-pharmacological approaches remain significantly underutilised in Malaysia, with only $10 \%$ of physicians indicating they would refer their patients for physiotherapy [43]. Under-recognising the benefit of non-pharmacological treatment options is a barrier to optimal patient management, and this consensus emphasises multi-specialty involvement in managing knee OA as different healthcare settings have varying access to indicated treatment modalities.

Specific to pharmacological background therapy, SYSA DOAs are currently not formally recommended in the Malaysian CPG. However, this consensus wishes to highlight the use of long-term SYSADOAs (specifically CGS) has been shown to consistently improve pain and physical function in knee OA; hence, their use as background 
pharmacological treatment for knee OA should be actively considered. In the panel's experience, most Malaysian physicians remain unaware of the key differences between the various commercially available formulations of SYSADOAs, underlining a potential gap in awareness that this consensus aims to address.

For patients who do not respond adequately to background treatment, they may be prescribed advanced pharmacological therapies - either as a monotherapy or concurrently (if indicated). Of particular interest, the National Survey on the Use of Medicines by Malaysian consumers found that up to $73.1 \%$ of respondents admitted to medication non-compliance [124, 125]. Physicians should thus prescribe the simplest treatment regimen whenever possible to optimise treatment adherence and minimise AEs. In contrast to other existing guidelines, this consensus differentiates the role of IAHA versus IACS therapies, which are indicated in patients at greater risk for NSAIDinduced AEs, or those who remain symptomatic despite the use of oral NSAIDs. In the absence of acute inflammation, the panel recommends viscosupplementation with IAHA, while IACS is the preferred choice in patients with active inflammation and/or effusion.

Overall, the choice of any single or multimodal intervention in knee OA may vary over the course of the disease, and treatment should be decided jointly between the patient and doctor. Doctors should always exercise caution when prescribing pharmacological agents, and management should begin with treatments with the least systemic exposure or toxicity.

A key feature of this consensus is the easy-to-follow one-page algorithm that illustrates the concurrent use of the recommended multimodal intervention to achieve optimal outcomes in patients with knee OA. The algorithm informs all healthcare providers of the options to combine multiple treatment modalities and step-up or step-down therapy as per patients' needs, which confers more flexibility in patient management compared with traditional step-up algorithms advocated by other guidelines. Additionally, this consensus includes only information that is relevant to the Malaysian population (e.g., types of pharmacological agents available) to provide healthcare providers with a direct source of reference to make informed decisions about individualised patient management strategy (Fig. 3).

The strength of this consensus lies in the synthesis of well-rounded recommendations based on evidence gathered from published literature and the extensive clinical experience of the expert panel in their respective fields. The panel comprised multi-speciality physicians who actively manage knee $\mathrm{OA}$ in different Malaysian healthcare settings and are aware of current real-world practices that may not be reflected in existing disease management guidelines.
On the other hand, a potential limitation of this consensus is the limited number of published clinical data that are specific to the Malaysian population. Therefore, recommendations made by the panel were mostly based on international guidelines that have been adapted to the Malaysian healthcare system. Moreover, evidence on the long-term efficacy of the multimodal treatment approach advocated by the panel remains sparse. However, the panel hopes that this study will serve as an important reference point to facilitate discussions on the potential benefits of adopting a flexible multimodal approach in managing patients with knee OA.

\section{Conclusions}

In conclusion, this consensus presents nine treatment recommendations and an algorithm for the management of knee OA. It is aimed at supporting all doctors involved in the care of patients with knee OA in Malaysia. In addition, this consensus could also be a useful guide for healthcare providers in other countries where knee $\mathrm{OA}$ is an increasingly common health problem.

\section{Acknowledgements}

Medical writing assistance was provided by KH Choong and TS Jong of MIMS (Malaysia), which was funded by Mylan Healthcare and complied with Good Publication Practice 3 ethical guidelines (Battisti et al. Ann Int Med 2015;163:461-464).

\section{Authors' contributions}

SSY and JKL were responsible for the conceptualisation of the project. SSY, JKL, SRAA, HB, KCC, VKML, NHMY, CCT and MPT drafted the manuscript, reviewed and revised it, and approved the final version.

\section{Funding}

This project was funded by an unrestricted educational grant from Mylan Healthcare Sdn. Bhd (a Viatris company). However, there were no representatives of Mylan Healthcare Sdn. Bhd. present during the expert panel discussions and they were not involved in the writing or approval of the manuscript.

\section{Availability of data and materials}

Data sharing is not applicable to this article as no datasets were generated or analysed during the current study.

\section{Declarations}

Ethics approval and consent to participate

Not applicable as per Guideline 1: Waiver for Medical Review \& Ethics Committee review and approval for research not involving human subject, released by the Ministry of Health Malaysia (31 Oct 2006).

\section{Consent for publication}

Not applicable.

\section{Competing interests}

Outside the submitted work: SSY reports personal fees from Amgen, Mylan \& Novartis, and non-financial support from Mylan \& Abbvie. SRAA reports personal fees from Mylan \& Pfizer. HB reports personal fees from Mylan, Roche, Sanofi, Boehringer-Ingelheim \& Pfizer. KCK reports personal fees from Abbott, Astra Zeneca, CIPLA, GSK, Mylan, Sanofi, Takeda and Xepa. JKL reports personal fees from Amgen \& Mylan. VKML reports personal fees from Mylan \& Sanofi Pasteur, and non-financial support from Mylan, Sanofi Pasteur \& Torrent. NHMY reports personal fees from Mylan, Hyphens, Zimmer \& Smith and Nephew. CCT reports personal fees from Mylan, Stryker \& Anthroworld. MPT reports personal fees from Mylan, Abbott, DCH Auriga, Pfizer \& Sanofi. 


\section{Author details}

'Department of Medicine, Subang Jaya Medical Centre, No. 1, Jalan SS12/1A, 47500 Subang Jaya, Selangor, Malaysia. ${ }^{2}$ Sport Medicine Unit, Hospital Selayang, 68100 Batu Caves, Selangor, Malaysia. ${ }^{3}$ Department of Internal Medicine, Universiti Teknologi MARA, Kampus Sungai Buloh, Jalan Hospital, 47000 Sungai Buloh, Selangor, Malaysia. ${ }^{4}$ Poliklinik Kepong Baru, Jalan Ambong Kiri Satu, Kepong Baru, 52100 Kuala Lumpur, Wilayah Persekutuan Kuala Lumpur, Malaysia. ${ }^{5}$ Department of Orthopaedic Surgery, Beacon Hospital, Jalan Templer, Section 51, 46050 Petaling Jaya, Selangor, Malaysia. ${ }^{6}$ Department of Family Medicine, School of Medicine, International Medical University, No. 126, Jalan Jalil Perkasa 19, Bukit Jalil, 57000 Kuala Lumpur, Wilayah Persekutuan Kuala Lumpur, Malaysia. ${ }^{7}$ Department of Orthopaedics and Traumatology, Faculty of Medicine, Universiti Kebangsaan Malaysia, Jalan Yaacob Latif, Bandar Tun Razak, 56000 Kuala Lumpur, Wilayah Persekutuan Kuala Lumpur, Malaysia. ${ }^{8}$ Department of Orthopaedic Surgery, Ara Damansara Medical Centre, Jalan Lapangan Terbang Subang, Seksyen U2, 40150 Shah Alam, Selangor, Malaysia. 'Department of Medicine, Faculty of Medicine, University of Malaya, 50603 Kuala Lumpur, Malaysia. ${ }^{10}$ Department of Medical Sciences, Faculty of Healthcare and Medical Sciences, Sunway University, 47500 Bandar Sunway, Selangor, Malaysia.

\section{Received: 15 September 2020 Accepted: 18 May 2021} Published online: 04 June 2021

\section{References}

1. Cross M, Smith E, Hoy D, Nolte S, Ackerman I, Fransen M, et al. The global burden of hip and knee osteoarthritis: estimates from the global burden of disease 2010 study. Ann Rheum Dis. 2014;73(7):1323-30. https://doi.org/1 0.1136/annrheumdis-2013-204763.

2. National Institute for Health and Care Excellence. Osteoarthritis: care and management. Clinical Guideline. 2014. https://www.nice.org.uk/guidance/ cg177. Accessed 8 Jul 2020.

3. Mat S, Razack AH, Lim J, Khong SY, Kamaruzzaman SB, Chin AV, et al. Factors determining the increased risk of falls in individuals with knee pain in the Malaysian elders longitudinal research (MELoR) study. Front Med. 2019;6:277. https://doi.org/10.3389/fmed.2019.00277.

4. Nüesch E, Dieppe $P$, Reichenbach $S$, Williams S, Iff S, Jüni P. All cause and disease specific mortality in patients with knee or hip osteoarthritis: population based cohort study. BMJ. 2011;342(mar08 2):638. https://doi. org/10.1136/bmj.d1165.

5. IHME/GHDx/Niz Hub. IHME/GHDx/Viz Hub. https://vizhub.healthdata.org/ gbd-compare. Accessed 15 June 2020.

6. Veerapen K, Wigley RD, Valkenburg H. Musculoskeletal pain in Malaysia: a COPCORD survey. J Rheumatol. 2007;34(1):207-13.

7. Malaysia Health Technology Assessment Section, Ministry of Health Malaysia. Clinical Practice Guidelines: Management of Osteoarthritis. http:// www.acadmed.org.my/index.cfm?\&menuid=67\#Rheumatology. Accessed 15 June 2020.

8. Department of Statistics M. Current Population Estimates, Malaysia, 20182019. 2019. https://www.dosm.gov.my. Accessed 15 June 2020

9. Department of Statistics M. Population Projection (Revised), Malaysia, 20102040. 2016. https://www.dosm.gov.my. Accessed 15 June 2020.

10. Institute for Public Health, Ministry of Health Malaysia. National Health and Morbidity Survey 2015 Vol. II: Non-Communicable Diseases, Risk Factors \& Other Health Problems. https://www.moh.gov.my/moh/resources/ nhmsreport2015vol2.pdf. Accessed 15 June 2020.

11. Felson D, Hannan M, Naimark A, Berkeley J, Gordon G, Wilson P, et al. Occupational physical demands, knee bending, and knee osteoarthritis: results from the Framingham study. J Rheumatol. 1991;18(10):1587-92.

12. Muraki S, Oka H, Akune T, En-yo Y, Yoshida M, Nakamura K, et al. Association of occupational activity with joint space narrowing and osteophytosis in the medial compartment of the knee: the ROAD study (OAC5914R2). Osteoarthr Cartil. 2011;19(7):840-6. https://doi.org/10.1016/j. joca.2011.03.008

13. Veerapen $\mathrm{K}$, Asokan RN, Rathakrishan V. Clinical and radiological profile of symptomatic knee osteoarthritis in Malaysia. APLAR J Rheumatol. 2004;7(2): 97-107. https://doi.org/10.1111/j.1479-8077.2004.00069.x.

14. Ahmad MA, Ajit Singh DK, Chua WQ, Abd Rahman NNA, Mohd Padzi F, Muhammad Hendri EN. Knee osteoarthritis and its related issues: patients' perspective. J Sains Kesihat Malaysia. 2018;16(si):171-7. https://doi.org/10.1 7576/jskm-2018-23.
15. Mimi O, Tong SF, Nordin S, Teng CL, Khoo EM, Abdul-Rahman AK, et al. A comparison of morbidity patterns in public and private primary care clinics in Malaysia. Malaysian Fam Physician. 2011;6:19-25.

16. Zailinawati AH, Teng CL, Kamil MA, Achike FI, Koh CN, Kamil Ariff K, et al. Pain morbidity in primary care - preliminary observations from two different primary care settings. Med J Malaysia. 2006;61(2):162-7.

17. Norris SL, Glasgow RE, Engelgau MM, O'Connor PJ, McCulloch D. Chronic disease management: a definition and systematic approach to component interventions. Dis Manage Health Outcomes. 2003;11(8):477-88. https://doi. org/10.2165/00115677-200311080-00001.

18. Bruyère $\mathrm{O}$, Honvo $\mathrm{G}$, Veronese $\mathrm{N}$, Arden NK, Branco J, Curtis EM, et al. An updated algorithm recommendation for the management of knee osteoarthritis from the European Society for Clinical and Economic Aspects of osteoporosis, osteoarthritis and musculoskeletal diseases (ESCEO). Semin Arthritis Rheum. 2019; 49(3):337-50. https://doi.org/10.1016/j.semarthrit.2019.04.008.

19. Kolasinski SL, Neogi T, Hochberg MC, Oatis C, Guyatt G, Block J, et al. 2019 American College of Rheumatology/Arthritis Foundation guideline for the Management of Osteoarthritis of the hand, hip, and knee. Arthritis Rheum. 2020;72(2):220-33. https://doi.org/10.1002/art.41142.

20. Attia A. Adaptation of international evidence based clinical practice guidelines: the ADAPTE process. Middle East Fertil Soc J. 2013;18(2):123-6. https://doi.org/10.1016/j.mefs.2013.03.002.

21. Dalkey NC. Rand. The Delphi method: an experimental study of group opinion. Santa Monica: Rand Corp; 1969.

22. Rosenfeld RM, Nnacheta LC, Corrigan MD. Clinical consensus statement development manual. Otolaryngol - Head Neck Surg (United States). 2015; 153(2 Suppl):S1-14. https://doi.org/10.1177/0194599815601394.

23. Messner AH, Walsh J, Rosenfeld RM, Schwartz SR, Ishman SL, Baldassari C, et al. Clinical consensus statement: Ankyloglossia in children. Otolaryngol Head Neck Surg (United States). 2020;162:597-611. https://doi.org/10.1177/ 0194599820915457.

24. Zhang W, Doherty M, Peat G, Bierma-Zeinstra SMA, Arden NK, Bresnihan B, et al. EULAR evidence-based recommendations for the diagnosis of knee osteoarthritis. Ann Rheum Dis. 2010;69(3):483-9. https://doi.org/10.1136/a rd.2009.113100.

25. Fernandes L, Hagen KB, Bijlsma JWJ, Andreassen O, Christensen P, Conaghan $P G$, et al. EULAR recommendations for the non-pharmacological core management of hip and knee osteoarthritis. Ann Rheum Dis. 2013; 72(7):1125-35. https://doi.org/10.1136/annrheumdis-2012-202745.

26. Hay EM, Foster NE, Thomas E, Peat G, Phelan M, Yates HE, et al. Effectiveness of community physiotherapy and enhanced pharmacy review for knee pain in people aged over 55 presenting to primary care: pragmatic randomised trial. BMJ. 2006;333(7576):995-8. https://doi.org/10.1136/bmj.38977.590752.0B.

27. Hurley MV, Walsh NE, Mitchell HL, Pimm TJ, Patel A, Williamson E, et al. Clinical effectiveness of a rehabilitation program integrating exercise, selfmanagement, and active coping strategies for chronic knee pain: a cluster randomized trial. Arthritis Care Res. 2007;57(7):1211-9. https://doi.org/10.1 002/art.22995.

28. Bannuru RR, Osani MC, Vaysbrot EE, Arden NK, Bennell K, Bierma-Zeinstra SMA, et al. OARSI guidelines for the non-surgical management of knee, hip, and polyarticular osteoarthritis. Osteoarthr Cartil. 2019;27(11):1578-89. https://doi.org/10.1016/j.joca.2019.06.011.

29. Georgiev T, Angelov AK. Modifiable risk factors in knee osteoarthritis: treatment implications. Rheumatol Int. 2019;39(7):1145-57. https://doi.org/1 0.1007/s00296-019-04290-z.

30. Shafii NAHN, Yaacob LH, Ishak A, Kadir AA. Traditional and complementary medicine use in knee osteoarthritis and its associated factors among patients in northeast peninsular Malaysia. Oman Med J. 2018;33(2):148-53. https://doi.org/10.5001/omj.2018.27.

31. Gay C, Chabaud A, Guilley E, Coudeyre E. Educating patients about the benefits of physical activity and exercise for their hip and knee osteoarthritis. Systematic literature review. Ann Phys Rehabil Med. 2016; 59(3):174-83. https://doi.org/10.1016/j.rehab.2016.02.005.

32. Messier SP, Resnik AE, Beavers DP, Mihalko SL, Miller GD, Nicklas BJ, et al. Intentional weight loss in overweight and obese patients with knee osteoarthritis: is more better? Arthritis Care Res. 2018;70(11):1569-75. https:// doi.org/10.1002/acr.23608.

33. Salwana Kamsan S, Kaur Ajit Singh D, Pin Tan M, Kumar S. Systematic review on the contents and parameters of self-management education programs in older adults with knee osteoarthritis. Australasian J Ageing. 2020;40. https://doi.org/10.1111/ajag.12844. 
34. Wellsandt E, Golightly Y. Exercise in the management of knee and hip osteoarthritis. Curr Opin Rheumatol. 2018;30(2):151-9. https://doi.org/10.1 097/BOR.0000000000000478.

35. Chang AH, Lee J, Chmiel JS, Almagor O, Song J, Sharma L. Association of Long-term Strenuous Physical Activity and Extensive Sitting with incident radiographic knee osteoarthritis. JAMA. 2020;3(5):e204049. https://doi.org/1 0.1001/jamanetworkopen.2020.4049.

36. Fransen M, McConnell S, Harmer AR, Van Der Esch M, Simic M, Bennell KL. Exercise for osteoarthritis of the knee: a Cochrane systematic review. $\mathrm{Br}$ J Sports Med. 2015;49(24):1554-7. https://doi.org/10.1136/bjsports-2015095424

37. Kang JW, Lee MS, Posadzki P, Ernst E. T'ai chi for the treatment of osteoarthritis: a systematic review and meta-analysis. BMJ Open. 2011;1(1): e000035. https://doi.org/10.1136/bmjopen-2010-000035.

38. Wang Y, Lu S, Wang R, Jiang P, Rao F, Wang B, et al. Integrative effect of yoga practice in patients with knee arthritis a PRISMA-compliant metaanalysis. Medicine (United States). 2018;97. https://doi.org/10.1097/MD. 0000000000011742.

39. Cudejko T, van der Esch M, van der Leeden M, Roorda L, Pallari J, Bennell K, et al. Effect of soft braces on pain and physical function in patients with knee osteoarthritis: systematic review with meta-analyses. Arch Phys Med Rehabil. 2018;99:153-63. https://doi.org/10.1016/j.joca.2017.02.671.

40. Mat S, Ng CT, Tan PJ, Ramli N, Fadzli F, Rozalli Fl, et al. Effect of modified Otago exercises on postural balance, fear of falling, and fall risk in older fallers with knee osteoarthritis and impaired Gait and balance: a secondary analysis. PM R. 2018;10(3):254-62. https://doi.org/10.1016/j.pmrj.2017.08.405.

41. Le Quintrec J-L, Verlhac B, Cadet C, Bréville P, Vetel JM, Gauvain JB, et al. Physical exercise and weight loss for hip and knee osteoarthritis in very old patients: a systematic review of the literature. Open Rheumatol J. 2014;8(1): 89-95. https://doi.org/10.2174/1874312901408010089.

42. Saengnipanthkul S, Waikakul S, Rojanasthien S, Totemchokchyakarn K, Srinkapaibulaya A, Cheh Chin T, et al. Differentiation of patented crystalline glucosamine sulfate from other glucosamine preparations will optimize osteoarthritis treatment. Int J Rheum Dis. 2019;22(3):376-85. https://doi. org/10.1111/1756-185X.13068.

43. Arshad A, Rashid R, Das GE. A survey of the primary care management of osteoarthritis in Malaysia: a view from a rheumatologist's perspective. Int J Rheum Dis. 2008;11(3):246-50. https://doi.org/10.1111/j.1756-185X.2 008.00367.x

44. De Wan M, Volpi G, inventors; Rottapharm, assignee. A method of preparing mixed glucosamine salts. US patent 5,847,107. https://patents.google.com/ patent/US5847107A/en. Accessed 6 May 2020.

45. Bruyère $\mathrm{O}$, Cooper C, Al-Daghri NM, Dennison EM, Rizzoli R, Reginster JY. Inappropriate claims from non-equivalent medications in osteoarthritis: a position paper endorsed by the European Society for Clinical and Economic Aspects of osteoporosis, osteoarthritis and musculoskeletal diseases (ESCEO). Aging Clin Exp Res. 2018;30(2):111-7. https://doi.org/10.1007/s40520-017-0861-1.

46. Towheed T, Maxwell L, Anastassiades TP, Shea B, Houpt JB, Welch V, et al Glucosamine therapy for treating osteoarthritis. Cochrane Database Syst Rev. 2005:(2):CD002946. https://doi.org/10.1002/14651858.CD002946.pub2.

47. Eriksen P, Bartels EM, Altman RD, Bliddal H, Juhl C, Christensen R. Risk of bias and brand explain the observed inconsistency in trials on glucosamine for symptomatic relief of osteoarthritis: a meta-analysis of placebocontrolled trials. Arthritis Care Res. 2014;66(12):1844-55. https://doi.org/10.1 $002 / a c r .22376$

48. Kucharz EJ, Kovalenko V, Szántó S, Bruyère O, Cooper C, Reginster JY. A review of glucosamine for knee osteoarthritis: why patented crystalline glucosamine sulfate should be differentiated from other glucosamines to maximize clinical outcomes. Curr Med Res Opin. 2016;32(6):997-1004. https://doi.org/10.1185/03007995.2016.1154521.

49. Herrero-Beaumont G, Román Ivorra JA, Trabado MDC, Blanco FJ, Benito P, Martìn-Mola E, et al. Glucosamine sulfate in the treatment of knee osteoarthritis symptoms: a randomized, double-blind, placebo-controlled study using acetaminophen as a side comparator. Arthritis Rheum. 2007; 56(2):555-67. https://doi.org/10.1002/art.22371.

50. Gregori D, Giacovelli G, Minto C, Barbetta B, Gualtieri F, Azzolina D, et al. Association of Pharmacological Treatments with long-term pain control in patients with knee osteoarthritis: a systematic review and meta-analysis. JAMA -J Am Med Assoc. 2018:320:2564-79.
51. Bannuru RR, Natov NS, Dasi UR, Schmid CH, McAlindon TE. Therapeutic trajectory following intra-articular hyaluronic acid injection in knee osteoarthritis - meta-analysis. Osteoarthr Cartil. 2011;19(6):611-9. https://doi. org/10.1016/j.joca.2010.09.014.

52. Reginster JY, Deroisy R, Rovati LC, Lee RL, Lejeune E, Bruyère O, et al. Longterm effects of glucosamine sulfate on osteoarthritis progression: a randomised, placebo-controlled clinical trial. Lancet. 2001;357(9252):251-6. https://doi.org/10.1016/S0140-6736(00)03610-2.

53. Pavelká K, Gatterová J, Olejarová M, Machacek S, Giacovelli G, Rovati LC. Glucosamine sulfate use and delay of progression of knee osteoarthritis: a 3-year, randomized, placebo-controlled, double-blind study. Arch Intern Med. 2002;162(18):2113-23. https://doi.org/10.1001/archinte.162.18.2113.

54. Rovati LC, Girolami F, D'Amato M, Giacovelli G. Effects of glucosamine sulfate on the use of rescue non-steroidal anti-inflammatory drugs in knee osteoarthritis: results from the Pharmaco-epidemiology of GonArthroSis (PEGASus) study. Semin Arthritis Rheum. 2016;45(4):S34-41. https://doi.org/1 0.1016/.j.semarthrit.2015.10.009

55. Bruyère O, Pavelka K, Rovati LC, Gatterová J, Giacovelli G, Olejarová M, et al. Total joint replacement after glucosamine sulfate treatment in knee osteoarthritis: results of a mean 8-year observation of patients from two previous 3-year, randomised, placebo-controlled trials. Osteoarthr Cartil. 2008;16(2):254-60. https://doi.org/10.1016/j.joca.2007.06.011.

56. Clegg DO, Reda DJ, Harris CL, Klein MA, O'Dell JR, Hooper MM, et al. Glucosamine, chondroitin sulfate, and the two in combination for painful knee osteoarthritis. N Engl J Med. 2006;354(8):795-808. https://doi.org/10.1 056/NEJMoa052771.

57. Reginster JYL, Bruyère $\mathrm{O}$, Cooper $\mathrm{C}$. Different glucosamine sulfate products generate different outcomes on osteoarthritis symptoms. Ann Rheum Dis. 2017;0:11-3.

58. Fransen M, Agaliotis M, Nairn L, Votrubec M, Bridgett L, Su S, et al. Glucosamine and chondroitin for knee osteoarthritis: a double-blind randomised placebo-controlled clinical trial evaluating single and combination regimens. Ann Rheum Dis. 2015;74(5):851-8. https://doi.org/1 0.1136/annrheumdis-2013-203954.

59. Zhu X, Sang L, Wu D, Rong J, Jiang L. Comparative effectiveness of glucosamine, chondroitin, acetaminophen or celecoxib for the treatment of knee and/or hip osteoarthritis: a network meta-analysis. Clin Exp Rheumatol. 2018;36(4):595-602.

60. Fidelix TSA, Macedo CR, Maxwell LJ, Fernandes Moça Trevisani V. Diacerein for osteoarthritis. Cochrane Database Syst Rev. 2014;(2):CD005117. https:// doi.org/10.1002/14651858.CD005117.pub3.

61. Kongtharvonskul J, Anothaisintawee T, McEvoy M, Attia J, Woratanarat P, Thakkinstian A. Efficacy and safety of glucosamine, diacerein, and NSAIDs in osteoarthritis knee: a systematic review and network meta-analysis. Eur J Med Res. 2015;20(1):24. https://doi.org/10.1186/s40001-015-0115-7.

62. Pavelka K, Bruyère $O$, Cooper C, Kanis JA, Leeb BF, Maheu E, et al. Diacerein: benefits, risks and place in the Management of Osteoarthritis. An opinionbased report from the ESCEO. Drugs Aging. 2016;33(2):75-85. https://doi. org/10.1007/s40266-016-0347-4.

63. Bartels EM, Bliddal H, Schøndorff PK, Altman RD, Zhang W, Christensen R. Symptomatic efficacy and safety of diacerein in the treatment of osteoarthritis: a meta-analysis of randomized placebocontrolled trials. Osteoarthr Cartil. 2010;18(3):289-96. https://doi.org/1 0.1016/j.joca.2009.10.006

64. Appelboom T, Schuermans J, Verbruggen G, Henrotin Y, Reginster JY Symptoms modifying effect of avocado/soybean unsaponifiables (ASU) in knee osteoarthritis: a double blind, prospective, placebo-controlled study. Scand J Rheumatol. 2001:30:242-7.

65. Simental-Mendía M, Sánchez-García A, Acosta-Olivo CA, Vilchez-Cavazos F, Osuna-Garate J, Peña-Martínez VM, et al. Efficacy and safety of avocadosoybean unsaponifiables for the treatment of hip and knee osteoarthritis: a systematic review and meta-analysis of randomized placebo-controlled trials. Int J Rheum Dis. 2019;22(9):1607-15. https://doi.org/10.1111/1756-1 $85 X .13658$.

66. Cameron M, Chrubasik S. Oral herbal therapies for treating osteoarthritis. Cochrane Database Syst Rev. 2014;2014:CD002947.

67. Honvo G, Reginster JY, Rabenda V, Geerinck A, Mkinsi O, Charles A, et al. Safety of symptomatic slow-acting drugs for osteoarthritis: outcomes of a systematic review and meta-analysis. Drugs Aging. 2019;36(Suppl 1):65-99. https://doi.org/10.1007/s40266-019-00662-z. 
68. Conaghan PG, Arden N, Avouac B, Migliore A, Rizzoli R. Safety of Paracetamol in osteoarthritis: what does the literature say? Drugs Aging. 2019;36(Suppl 1):7-14. https://doi.org/10.1007/s40266-019-00658-9.

69. Remy C, Marret E, Bonnet F. State of the art of paracetamol in acute pain therapy. Curr Opin Anaesthesiol. 2006;19(5):562-5. https://doi.org/10.1097/ 01.aco.0000245285.30282.70.

70. Leopoldino AO, MacHado GC, Ferreira PH, Pinheiro MB, Day R, McLachlan $\mathrm{AJ}$, et al. Paracetamol versus placebo for knee and hip osteoarthritis. Cochrane Database Syst Rev. 2019;2:CD013273.

71. Bannuru RR, Schmid CH, Kent DM, Vaysbrot EE, Wong JB, McAlindon TE. Comparative effectiveness of pharmacologic interventions for knee osteoarthritis: a systematic review and network meta-analysis. Ann Intern Med. 2015;162(1):46-54. https://doi.org/10.7326/M14-1231.

72. Roberts E, Nunes VD, Buckner S, Latchem S, Constanti M, Miller $P$, et al. Paracetamol: not as safe as we thought? A systematic literature review of observational studies. Ann Rheum Dis. 2016;75(3):552-9. https://doi.org/1 0.1136/annrheumdis-2014-206914.

73. de Vries F, Setakis E, van Staa TP. Concomitant use of ibuprofen and paracetamol and the risk of major clinical safety outcomes. Br J Clin Pharmacol. 2010;70(3):429-38. https://doi.org/10.1111/j.1365-2125.2010. 03705.x.

74. Kurth T, Glynn RJ, Walker AM, Rexrode KM, Buring JE, Stampfer MJ, et al. Analgesic use and change in kidney function in apparently healthy men. Am J Kidney Dis. 2003;42(2):234-44. https://doi.org/10.1016/S0272-6386(03)00647-4.

75. Kanchanasurakit S, Arsu A, Siriplabpla W, Duangjai A, Saokaew S. Acetaminophen use and risk of renal impairment: a systematic review and meta-analysis. Kidney Res Clin Pract. 2020;39(1):81-92. https://doi.org/10.23 876/j.krcp.19.106.

76. Lin J, Zhang W, Jones A, Doherty M. Efficacy of topical non-steroidal antiinflammatory drugs in the treatment of osteoarthritis: meta-analysis of randomised controlled trials. Br Med J. 2004;329(7461):324-6. https://doi. org/10.1136/bmj.38159.639028.7C.

77. Derry S, Conaghan P, Da Silva JAP, Wiffen PJ, Moore RA. Topical NSAIDs for chronic musculoskeletal pain in adults. Cochrane Database Syst Rev. 2016;4: CD007400.

78. Derry S, Wiffen PJ, Kalso EA, Bell RF, Aldington D, Phillips T, et al. Topical analgesics for acute and chronic pain in adults - an overview of Cochrane reviews. Cochrane Database Syst Rev. 2017;5:CD008609.

79. Zeng C, Wei J, Persson MSM, Sarmanova A, Doherty M, Xie D, et al. Relative efficacy and safety of topical non-steroidal anti-inflammatory drugs for osteoarthritis: a systematic review and network meta-analysis of randomised controlled trials and observational studies. Br J Sports Med. 2018;52(10):64250. https://doi.org/10.1136/bjsports-2017-098043.

80. Chou R, McDonagh M, Nakamoto E, Griffin J. Analgesics for osteoarthritis: an update of the 2006 comparative effectiveness review. Agency Healthc Res Qual. 2011; http://www.ncbi.nlm.nih.gov/pubmedhealth/PMH0016485/pdf/ TOC.pdf. Accessed 20 May 2020.

81. Honvo G, Leclercq V, Geerinck A, Thomas T, Veronese N, Charles A, et al. Safety of topical non-steroidal anti-inflammatory drugs in osteoarthritis: outcomes of a systematic review and meta-analysis. Drugs Aging. 2019; 36(Suppl 1):45-64. https://doi.org/10.1007/s40266-019-00661-0.

82. Pelletier JP, Martel-Pelletier J, Rannou F, Cooper C. Efficacy and safety of oral NSAIDs and analgesics in the management of osteoarthritis: evidence from real-life setting trials and surveys. Semin Arthritis Rheum. 2016;45(4):S22-7. https://doi.org/10.1016/j.semarthrit.2015.11.009.

83. da Costa BR, Reichenbach S, Keller N, Nartey L, Wandel S, Jüni P, et al. Effectiveness of non-steroidal anti-inflammatory drugs for the treatment of pain in knee and hip osteoarthritis: a network meta-analysis. Lancet. 2017; 390(10090):e21-33. https://doi.org/10.1016/S0140-6736(17)31744-0.

84. Cooper C, Chapurlat R, Al-Daghri N, Herrero-Beaumont G, Bruyère O, Rannou F, et al. Safety of Oral non-selective non-steroidal anti-inflammatory drugs in osteoarthritis: what does the literature say? Drugs Aging. 2019; 36(Suppl 1):15-24. https://doi.org/10.1007/s40266-019-00660-1.

85. Puljak L, Marin A, Vrdoljak D, Markotic F, Utrobicic A, Tugwell P. Celecoxib for osteoarthritis. Cochrane Database Syst Rev. 2017;5:CD009865.

86. Baigent C, Bhala N, Emberson J, Merhi A, Abramson S, Arber N, et al. Vascular and upper gastrointestinal effects of non-steroidal antiinflammatory drugs: meta-analyses of individual participant data from randomised trials. Lancet. 2013;382:769-79.

87. Wang $X$, Tian HJ, Yang HK, Wanyan P, Peng YJ. Meta-analysis: Cyclooxygenase-2 inhibitors are no better than nonselective nonsteroidal anti-inflammatory drugs with proton pump inhibitors in regard to gastrointestinal adverse events in osteoarthritis and rheumatoid arthritis. Eur J Gastroenterol Hepatol. 2011;23(10):876-80. https://doi.org/10.1097/MEG. Ob013e328349de81.

88. Ungprasert P, Cheungpasitporn W, Crowson CS, Matteson EL. Individual non-steroidal anti-inflammatory drugs and risk of acute kidney injury: a systematic review and meta-analysis of observational studies. Eur J Intern Med. 2015;26(4):285-21. https://doi.org/10.1016/j.ejim.2015.03.008.

89. Burmester GR, Lanas A, Biasucci L, Hermann M, Lohmander S, Olivieri I, et al. The appropriate use of non-steroidal antiinflammatory drugs in rheumatic disease: opinions of a multidisciplinary European expert panel. Ann Rheum Dis. 2011;70(5):818-22. https://doi.org/10.1136/ard.2010.128660.

90. Bellamy N, Campbell J, Robinson V, Gee T, Bourne R, Wells G. Viscosupplementation for the treatment of osteoarthritis of the knee. Cochrane Database Syst Rev. 2005;(2):CD005321. https://doi.org/10.1002/14 651858.CD005321

91. Maheu E, Rannou F, Reginster J. Efficacy and safety of hyaluronic acid in the management of osteoarthritis : evidence from real-life setting trials and surveys. Semin Arthritis Rheum. 2016;45(4):S28-33. https://doi.org/10.1016/j. semarthrit.2015.11.008.

92. Narayanan S, Suhail A, Harjeet S, Shahril Y, Masbah O. Efficacy of intraarticular injection of hyaluronic acid in the treatment of knee osteoarthritis. Malaysian Orthop J. 2009;3(1):19-23. https://doi.org/10.5704/MOJ.0905.002.

93. Bannuru RR, Schmid CH, Kent DM, Vaysbrot EE, Wong JB, McAlindon TE. Comparative effectiveness of pharmacologic interventions for knee osteoarthritis. Ann Intern Med. 2015;162(1):46-54. https://doi.org/10.7326/ M14-1231.

94. Richette P, Chevalier X, Ea HK, Eymard F, Henrotin Y, Ornetti P, et al. Hyaluronan for knee osteoarthritis: an updated meta-analysis of trials with low risk of bias. Rheum Musculoskelet Dis. 2015;1:e000071.

95. Yoga R, Mukaram M. Ramachandran. Intrarticular sodium hyaluronate for the treatment of osteoarthritis of the knee. A retrospective review of 45 patients. Malaysian Orthop J. 2009;3(2):4-7. https://doi.org/10.5704/MOJ. 0911.001.

96. Cooper C, Rannou OIS, Richette P, Ere OB, Al-daghri N, Altman ROYD, et al. Use of Intraarticular hyaluronic acid in the Management of Knee Osteoarthritis in clinical practice. Arthritis Ann Intern Med Care Res. 2017; 69(9):1287-96. https://doi.org/10.1002/acr.23204.

97. Altman R, Lim S, Steen RG, Dasa V. Hyaluronic acid injections are associated with delay of Total knee replacement surgery in patients with knee osteoarthritis : evidence from a large U.S. health claims database. PLoS One. 2015;10(12):e0145776. https://doi.org/10.1371/journal.pone.0145776.

98. Altman R, Fredericson M, Bhattacharyya SK, Bisson B, Abbott T, Yadalam MBAS, et al. Association between hyaluronic acid injections and time-toTotal knee replacement surgery. J Knee Surg. 2016;29(7):564-70. https://doi. org/10.1055/s-0035-1568992.

99. Delbarre A, Amor B, Bardoulat I, Tetafort A, Pelletier-fleury N. Do intraarticular hyaluronic acid injections delay total knee replacement in patients with osteoarthritis - a cox model analysis. PLoS One. 2017;12(11):e0187227. https://doi.org/10.1371/journal.pone.0187227.

100. Bannuru RR, Osani M, Vaysbrot EE, Mcalindon TE. Comparative safety profile of hyaluronic acid products for knee osteoarthritis: a systematic review and network meta-analysis. Osteoarthr Cartil. 2016;24(12):2022-41. https://doi. org/10.1016/j.joca.2016.07.010.

101. Jüni $P$, Hari R, Rutjes AW, Fischer R, Silletta MG, Reichenbach $S$, da Costa BR. Intra-articular corticosteroid for knee osteoarthritis. Cochrane Database Syst Rev. 2015;(10):CD005328. https://doi.org/10.1002/14651858.CD005328.pub3.

102. Maricar N, Parkes MJ, Callaghan MJ, Hutchinson CE, Gait AD, Hodgson R, et al. Structural predictors of response to intra-articular steroid injection in symptomatic knee osteoarthritis. Arthritis Res Ther. 2017;19(1):88. https://doi. org/10.1186/s13075-017-1292-2.

103. He W, Kuang M, Zhao J, Sun L, Lu B, Wang Y, et al. Ef fi cacy and safety of intraarticular hyaluronic acid and corticosteroid for knee osteoarthritis : a meta-analysis. Int J Surg. 2017;39:95-103. https://doi.org/10.1016/j.ijsu.2017. 01.087.

104. Mcalindon TE, Lavalley MP, Harvey WF, Price LL, Driban JB, Zhang M, et al. Effect of intra-articular triamcinolone vs saline on knee cartilage volume and pain in patients with knee osteoarthritis: a randomized clinical trial. JAMA. 2017;02111:1967-75

105. Bannuru RR, Natov NS, Obadan ISIE, Price LL, Schmid CH, Alindon TEMC, et al. Therapeutic trajectory of hyaluronic acid versus corticosteroids in the 
treatment of knee osteoarthritis : a systematic review and meta-analysis. Arthritis Rheum. 2009;61(12):1704-11. https://doi.org/10.1002/art.24925.

106. Legré-Boyer V. Viscosupplementation: techniques, indications, results. Orthop Traumatol Surg Res. 2015;101(1):S101-8. https://doi.org/10.1016/j. otsr.2014.07.027

107. Megale RZ, Deveza LA, Blyth FM, Naganathan V, Ferreira PH, McLachlan AJ, et al. Efficacy and safety of Oral and transdermal opioid analgesics for musculoskeletal pain in older adults: a systematic review of randomized, placebo-controlled trials. J Pain. 2018;19:475.e1-475.e24.

108. Smith SR, Deshpande BR, Collins JE, Katz JN, Losina E. Comparative pain reduction of oral non-steroidal anti-inflammatory drugs and opioids for knee osteoarthritis: systematic analytic review. Osteoarthr Cartil. 2016;24(6): 962-72. https://doi.org/10.1016/j.joca.2016.01.135.

109. Stewart M, Cibere J, Sayre EC, Kopec JA. Efficacy of commonly prescribed analgesics in the management of osteoarthritis: a systematic review and meta-analysis. Rheumatol Int. 2018;38(11):1985-97. https://doi.org/10.1007/ s00296-018-4132-z.

110. Toupin AK, Bisaillon J, Welch V, Maxwell LJ, Jüni P, Rutjes AWS, et al. Tramadol for osteoarthritis. Cochrane Database Syst Rev. 2019;5(5): CD005522. https://doi.org/10.1002/14651858.CD005522.pub3.

111. Fuggle $N$, Curtis E, Shaw S, Spooner L, Bruyère O, Ntani G, et al. Safety of opioids in osteoarthritis: outcomes of a systematic review and meta-analysis. Drugs Aging. 2019;36(S1):129-43. https://doi.org/10.1007/s40266-019-00666-9.

112. Tagarro I, Herrera J, Barutell C, Díez MC, Marín M, Samper D, et al. Effect of a simple dose-escalation schedule on tramadol tolerability: assessment in the clinical setting. Clin Drug Investig. 2005;25(1):23-31. https://doi.org/10.2165/ 00044011-200525010-00003.

113. Choi CB, Song JS, Kang YM, Suh CH, Lee J, Choe JY, et al. A 2-week, multicenter, randomized, double-blind, double-dummy, add-on study of the effects of titration on tolerability of tramadol/acetaminophen combination tablet in Korean adults with knee osteoarthritis pain. Clin Ther. 2007;29(7): 1381-9. https://doi.org/10.1016/j.clinthera.2007.07.015.

114. Park HR, Cho SK, Im SG, Jung SY, Kim D, Jang EJ, et al. Treatment patterns of knee osteoarthritis patients in Korea. Korean J Intern Med. 2019;34(5):114553. https://doi.org/10.3904/kjim.2017.304.

115. Silverfield JC, Kamin M, Wu SC, Rosenthal N. Tramadol/acetaminophen combination tablets for the treatment of osteoarthritis flare pain: a multicenter, outpatient, randomized, double-blind, placebo-controlled, parallel-group, add-on study. Clin Ther. 2002;24(2):282-97. https://doi.org/1 0.1016/S0149-2918(02)85024-X.

116. García Rodríguez LA, Hernández-Díaz S. The risk of upper gastrointestinal complications associated with nonsteroidal anti-inflammatory drugs, glucocorticoids, acetaminophen, and combinations of these agents. Arthritis Res. 2001;3(2):98-101. https://doi.org/10.1186/ar146.

117. Liu CY, Li CD, Wang L, Ren S, Bin YF, Li JG, et al. Function scores of different surgeries in the treatment of knee osteoarthritis: a PRISMA-compliant systematic review and network-meta analysis. Medicine (United States). 2018;97:e10828.

118. Bruyère $O$, Ethgen $O$, Neuprez $A$, Zègels $B$, Gillet $P$, Huskin JP, et al. Healthrelated quality of life after total knee or hip replacement for osteoarthritis: a 7-year prospective study. Arch Orthop Trauma Surg. 2012;132(11):1583-7. https://doi.org/10.1007/s00402-012-1583-7.

119. Shan L, Shan B, Suzuki A, Nouh F, Saxena A. Intermediate and long-term quality of life after total knee replacement: a systematic review and meta-analysis. J Bone Jt Surg Am. 2015;97(2):156-68. https://doi.org/10.2106/JBJS.M.00372.

120. Gademan MGJ, Hofstede SN, Vliet Vlieland TPM, Nelissen RGHH, Marang-Van de Mheen PJ. Indication criteria for total hip or knee arthroplasty in osteoarthritis: a state-of-the-science overview. BMC Musculoskelet Disord. 2016;17:1-11.

121. Aweid O, Haider Z, Saed A, Kalairajah Y. Treatment modalities for hip and knee osteoarthritis: a systematic review of safety. J Orthop Surg. 2018;26(3): 230949901880866. https://doi.org/10.1177/2309499018808669.

122. Shah NZ, Malhotra R, Choon C, By JS, Chee H, Shen L, et al. Ethnic differences in preoperative patient characteristics and postoperative functional outcomes after Total knee Arthroplasty among Chinese, Malays and Indians. Ann Acad Med Singap. 2018;47:201-5.

123. Thambiah MD, Nathan S, Seow BZ, Liang S, Lingaraj K. Patient satisfaction after total knee arthroplasty: an Asian perspective. Singap Med J. 2015 56(05):259-63. https://doi.org/10.11622/smedj.2015074.

124. Gunaratne R, Pratt DN, Banda J, Fick DP, Khan RJK, Robertson BW. Patient dissatisfaction following Total knee Arthroplasty: a systematic review of the literature. J Arthroplast. 2017;32(12):3854-60. https://doi.org/10.1016/j.arth.2 017.07.021.

125. Pharmaceutical Services Division, Ministry of Health Malaysia. A National Survey On The Use of Medicines III (NSUM III) By Malaysian Consumers 2015. https:// www.pharmacy.gov.my/v2/en/documents/national-survey-use-medicines-iiinsum-iii-malaysian-consumers-2015.html. Accessed 29 Mar 2021.

\section{Publisher's Note}

Springer Nature remains neutral with regard to jurisdictional claims in published maps and institutional affiliations.

\section{Ready to submit your research? Choose BMC and benefit from:}

- fast, convenient online submission

- thorough peer review by experienced researchers in your field

- rapid publication on acceptance

- support for research data, including large and complex data types

- gold Open Access which fosters wider collaboration and increased citations

- maximum visibility for your research: over $100 \mathrm{M}$ website views per year

At BMC, research is always in progress.

Learn more biomedcentral.com/submissions 